\title{
1 Nuclear RNA binding regulates TDP-43 nuclear localization and passive nuclear export
}

4 Lauren Duan ${ }^{1}$, Benjamin L. Zaepfel ${ }^{2}$, Vasilisa Aksenova ${ }^{3}$, Mary Dasso ${ }^{3}$, Jeffrey D. Rothstein ${ }^{1,4}$, Petr

$5 \quad$ Kalab $^{5 *}$, Lindsey R. Hayes ${ }^{1,4 *}$

1-Brain Science Institute, Johns Hopkins University School of Medicine, Baltimore, MD 21205, USA

2-Biochemistry, Cellular and Molecular Biology Program, Johns Hopkins University School of Medicine,

Baltimore, MD 21205, USA

11 3-Division of Molecular and Cellular Biology, National Institute of Child Health and Human Development,

12 National Institutes of Health, Bethesda, MD 20892, USA

13 4-Department of Neurology, Johns Hopkins University School of Medicine, Baltimore, MD 21205, USA

14 5-Department of Chemical and Biomolecular Engineering, Whiting School of Engineering, Johns Hopkins

15 University, Baltimore, MD 21218, USA

16

17

18 


\section{Abstract}

30 Nuclear clearance of the DNA/RNA-binding protein TDP-43 is a pathologic hallmark of amyotrophic lateral

31 sclerosis and frontotemporal dementia that remains unexplained. Moreover, our current understanding of

32 TDP-43 nucleocytoplasmic shuttling does not fully explain the predominantly nuclear localization of TDP-43

33 in healthy cells. Here, we used permeabilized and live-cell models to investigate TDP-43 nuclear export

34 and the role of RNA in TDP-43 localization. We show that TDP-43 nuclear efflux occurs in low-ATP

35 conditions and independent of active mRNA export, consistent with export by passive diffusion through nuclear pore channels. TDP-43 nuclear residence requires binding to GU-rich nuclear intronic pre-mRNAs, based on the induction of TDP-43 nuclear efflux by RNase and GU-rich oligomers and TDP-43 nuclear retention conferred by pre-mRNA splicing inhibitors. Mutation of TDP-43 RNA recognition motifs disrupts TDP-43 nuclear accumulation and abolishes transcriptional blockade-induced TDP-43 nuclear efflux, demonstrating strict dependence of TDP-43 nuclear localization on RNA binding. Thus, the nuclear

41 abundance of GU-rich intronic pre-mRNAs, as dictated by the balance of transcription and pre-mRNA

42 processing, regulates TDP-43 nuclear sequestration and availability for passive nuclear export.

Keywords: nuclear transport / RNA / splicing / TDP-43 / transcription 
Introduction

58 Transactive response DNA binding protein $43 \mathrm{kD}$ (TDP-43) is an essential DNA/RNA-binding protein that 59 plays a major role in RNA processing and stability (reviewed in Prasad et al., 2019; François-Moutal et al, 60 2019). Loss of nuclear TDP-43 expression and accumulation of cytoplasmic aggregates is a pathologic 61 hallmark of amyotrophic lateral sclerosis (ALS) and frontotemporal dementia (FTD) (Neumann et al, 2006;

62 Arai et al, 2006), where approximately $97 \%$ and $45 \%$ of cases show TDP-43 pathology at autopsy,

63 respectively (reviewed in Ling et al., 2013). Substantial evidence links TDP-43 disruption to the pathogenesis of ALS and FTD, via loss of nuclear splicing regulation (Polymenidou et al, 2011; Tollervey et al, 2011; Ling et al, 2015) and the toxic effects of cytoplasmic aggregates (reviewed in Vanden Broeck et al., 2014; Prasad et al, 2019). Mutations in TDP-43 have been identified in families with inherited ALS (Kabashi et al, 2008; Sreedharan et al, 2008; Deerlin et al, 2008; Gitcho et al, 2008) and FTD (Borroni et al, 2009; Kovacs et al, 2009) and cause neurodegeneration in disease models (reviewed in Buratti, 2015), supporting a role for TDP-43 disruption in the evolution of disease. Remarkably, the vast majority of ALS and FTD cases involving TDP-43 cytoplasmic mislocalization are not associated with TDP-43 mutations,

71 indicating that diverse genetic, environmental, or age-related causes, possibly all involved in the same underlying process, drive the nuclear clearance of TDP-43 in disease. However, the factor(s) responsible for TDP-43 nuclear accumulation in healthy cells and mislocalization in ALS/FTD remain unclear.

TDP-43 is a member of the heterogenous ribonucleoprotein (hnRNP) family of RNA binding proteins (RBPs) that contains an N-terminal bipartite nuclear localization signal (NLS), two RNA recognition mofits (RRM1 and RRM2), and an intrinsically disordered C-terminal domain (reviewed in François-Moutal et al, 2019). RNA crosslinking and immunoprecipitation (CLIP-seq) studies show that TDP-43 preferentially binds GU-rich RNA motifs, particularly within introns (Polymenidou et al, 2011; Tollervey et al, 2011), consistent with its essential role in regulating alternative splicing and repression of cryptic exons (Ling et al, 2015).

81 Like many hnRNPs, TDP-43 continuously shuttles between the nucleus and cytoplasm (Ayala et al, 2008). 2008; Nishimura et al, 2010). A modest degree of passive nuclear import also likely occurs based on size 
85 Winton et al, 2008). TDP-43 nuclear export was initially thought to occur via the exportin-1 (XPO1) receptor

86 and a putative nuclear export signal (NES) in RRM2 (Winton et al, 2008). However, several groups recently

87 showed that NES deletions do not disrupt TDP-43 export, nor does XPO1 knockdown or inhibition by

88 selective inhibitors of nuclear export (Ederle et al, 2018; Pinarbasi et al, 2018; Archbold et al, 2018).

89 Adding 54-119 kD tags to TDP-43 strongly slowed its export, as would be expected for a passive export

90 mechanism rather than an energy-dependent, active process (Pinarbasi et al, 2018; Ederle et al, 2018).

91 Meanwhile, transcriptional blockade promotes TDP-43 nuclear efflux (Ayala et al, 2008; Ederle et al, 2018),

92 as does overexpression of the mRNA export receptor NXF1 (Archbold et al, 2018), suggesting a role for

93 nuclear RNA in mediating TDP-43 nuclear localization and raising the possibility of TDP-43 co-export with

94 mRNA, perhaps via the TREX (TRanscription/EXport) pathway (discussed in Ederle \& Dormann, 2017).

Here, we aimed to elucidate the mechanism of TDP-43 nuclear export and test the hypothesis that TDP-43 nuclear residence depends on its preferential binding to nuclear RNAs. Consistent with this idea, we found that RNase-mediated nuclear RNA degradation in permeabilized cells markedly disrupted TDP-43 nuclear sequestration, allowing TDP-43 to diffuse from the nucleus in low-ATP conditions. Moreover, in permeabilized and live cell assays, introduction of GU-rich oligomers induced TDP-43 exit from the

101 nucleus, likely by competitive dissociation from endogenous nuclear RNAs. Inhibition of pre-mRNA splicing 102 caused dose-dependent TDP-43 nuclear accumulation and prevented its nuclear export upon

103 transcriptional blockade, further supporting the notion that nuclear accumulation of TDP-43 depends on its 104 association with pre-mRNAs. Taken together, our results indicate that binding to GU-rich intronic pre105 mRNAs retains TDP-43 within nuclei and dictates its availability for passive diffusion from the nucleus.

\section{Results}

108 NVP-2-induced RNA Pol II inhibition promotes rapid TDP-43 nuclear export

109 Actinomycin D, a DNA-intercalating agent and pan-transcriptional inhibitor, has been shown to induce the 110 nuclear efflux of a subset of nuclear RNA-binding proteins (RBPs) including hnRNPA1 (Piñol-Roma \& 111 Dreyfuss, 1992), SR proteins (Cáceres et al, 1998), and TDP-43 (Ayala et al, 2008; Ederle et al, 2018). To 112 confirm that TDP-43 nuclear accumulation is sensitive to inhibition of mRNA synthesis and avoid the 
113 possible pleiotropic effects of DNA intercalation, we treated HeLa cells with NVP-2, an inhibitor of CDK9-

114 dependent RNA Polymerase II activation (Olson et al, 2018) and monitored TDP-43 localization by

115 immunostaining (Fig 1A-C). RNA synthesis was analyzed in parallel via a brief pulse of 5-ethynyl-uridine

116 (5-EU) prior to fixation, to facilitate 'click-chemistry' labeling of newly transcribed RNAs (Jao \& Salic, 2008).

117 Cells were imaged with an automated high-content spinning disc confocal microscope, and a translocation

118 algorithm was used to quantify the background-corrected fluorescence intensity in the nuclear and

119 cytoplasmic compartments (Hayes et al, 2020). Like actinomycin D (Suppl fig 1A-C), NVP-2 caused

120 progressive, dose-dependent inhibition of RNA synthesis (Fig 1A-B), sparing RNA puncta within nucleoli

121 resulting from RNA polymerase I-dependent ribosomal RNA synthesis (Fig 1A arrows) (Sharifi \& Bierhoff,

122 2018). In parallel, there was progressive TDP-43 nuclear efflux, as measured by a decrease in the nuclear

123 to cytoplasmic (N/C) ratio (Fig 1A,C). Importantly, the drop in the TDP-43 N/C ratio induced by both NVP-2

124 and actinomycin D corresponded to a decrease in nuclear immunofluorescence and an increase in

125 cytoplasmic immunofluorescence (Suppl fig 1D-E), consistent with TDP-43 translocation from the nucleus

126 to the cytoplasm. NVP-2 and actinomycin D treatment of mouse primary cortical neurons also induced

127 time- and dose-dependent transcriptional inhibition and TDP-43 nuclear efflux (suppl fig 1F-J).

129 Next, we compared the effect of NVP-2 on the localization of TDP-43 versus a panel of other RBPs,

130 including hnRNPs, RNA export proteins, members of the exon-junction complex, and splicing-associated

131 proteins (Fig 1D and Suppl fig 2A-B). Cells were treated with NVP-2 for up to $6 \mathrm{~h}$, fixed, and RBP

132 localization was analyzed by immunofluorescence and automated high-content analysis. RBP responses

133 were diverse, including rapid nuclear efflux (TDP-43, HuR), slow nuclear efflux (FUS, hnRNPA1), and no

134 change (Matrin-3). DDX19b, an ATP-dependent RNA helicase in the mRNA export pathway that is tethered

135 to the NPC (Napetschnig et al, 2009; Hodge et al, 2011) was unchanged, serving as an internal control for

136 nuclear stability. hnRNPC, a resident nuclear hnRNP that does not exhibit N/C shuttling (Piñol-Roma \&

137 Dreyfuss, 1992; Ederle et al, 2018) showed nuclear accumulation. Interestingly, TDP-43 was among the

138 most highly responsive RBPs to transcriptional blockade, suggesting strict dependence on nascent nuclear

139 RNA levels. 
141 TDP-43 exits the nucleus by passive diffusion

142 Recent studies showed that TDP-43 nuclear export is independent of the XPO1 nuclear export pathway 143 (Archbold et al, 2018; Pinarbasi et al, 2018; Ederle et al, 2018) and may passively leave the nucleus in a 144 size-limited manner (Pinarbasi et al, 2018; Ederle et al, 2018). In support of this, we found that the addition 145 of a relatively small 27-kD YFP tag markedly inhibited NVP-2-induced TDP-43 nuclear efflux (Suppl fig $146 \mathrm{1K})$. However, the mechanism of passive versus active TDP-43 export across the NPC remains to be 147 confirmed. Permeabilized cell assays have been widely used to study nucleocytoplasmic transport, 148 facilitating investigations of transport mechanisms in isolation from other cellular processes and permitting 149 a broad range of experimental perturbations (Adam et al, 1990; Cassany \& Gerace, 2009). Most 150 commonly, digitonin is used to selectively perforate the plasma membrane (Colbeau et al, 1971; Adam et $151 \mathrm{al}, 1990)$, releasing the cytoplasm and leaving the nuclear membrane and NPCs intact and able to perform 152 either passive or energy-dependent bidirectional transport (Hayes et al, 2020). Here, we developed an 153 assay for the passive nuclear export of endogenous TDP-43 in digitonin-permeabilized HeLa cells (Fig 154 2A). Post-permeabilization, cells were incubated in energy-free buffer and fixed at regular intervals to 155 analyze the localization of TDP-43 by immunofluorescence. Nuclear envelope and NPC integrity was 156 monitored by verifying that nuclei restrict the entry of a $70 \mathrm{kD}$ fluorescent dextran (Suppl fig $3 \mathbf{A}$ ), since the 157 permeability barrier of the NPC increasingly excludes cargoes above 30-60 kD (Mohr et al, 2009; Timney 158 et al, 2016). Using a luciferase-based reporter assay, we analyzed ATP levels following permeabilization 159 and found that the total ATP concentration drops by $~ 97 \%$ immediately after digitonin treatment, compared 160 to intact HeLa cells (Suppl fig 3B), confirming low ATP levels in the permeabilized cell system.

162 Next, we identified conditions permissive of TDP-43 nuclear export. Upon plasma membrane 163 permeabilization and maintenance in buffer, with no added transport receptors or ATP, we saw a 164 progressive decrease in nuclear TDP-43 immunofluorescence, to about $50 \%$ after $1 \mathrm{~h}$, in cells heated to a 165 physiological temperature at $37^{\circ} \mathrm{C}$ (Fig. 2B-C). However, there was only minimal change in nuclear TDP-43 over an identical time period when cells were permeabilized and kept at $4^{\circ} \mathrm{C}$. These results indicate that, while TDP-43 can passively leave the nucleus in low-ATP conditions at $37^{\circ} \mathrm{C}$, temperature-sensitive mechanism(s) hinder TDP-43 nuclear exit at 4ํㅡㄹ beyond the expected $\sim$ linear reduction of free diffusion 
169 with reduced temperature (Soh et al, 2010). To further test the passive nature of the observed export, we

170 added 1,6-hexanediol, an aliphatic alcohol that reversibly disrupts the phenylalanine-glycine (FG)-

171 permeability barrier lining the central channel of the NPC (Ribbeck \& Görlich, 2002). 1,6-hexanediol caused

172 a marked, dose-dependent acceleration of TDP-43 nuclear efflux, suggesting that nuclear pore

173 permeability is a rate-limiting factor in TDP-43 nuclear export (Fig. 2D-E). Interestingly, 1,6-hexanediol

174 accelerated TDP-43 nuclear exit not only at $37^{\circ} \mathrm{C}$ but also at $4^{\circ} \mathrm{C}$, suggesting that the FG-repeat

175 permeability barrier is temperature-sensitive and contributes, at least in part, to the hindrance of TDP-43

176 passive export at $4^{\circ} \mathrm{C}$. Of note, 1,6-hexanediol also reversibly inhibits TDP-43 liquid-liquid phase separation

177 (LLPS) over the concentration range used (Gopal et al, 2017; Mann et al, 2019). Dissolution of nuclear

178 TDP-43 phase condensates could also contribute to the acceleration of TDP-43 nuclear export if LLPS

179 affects the availability of TDP-43 monomers for diffusion across the NPC, which remains to be investigated.

180 Consistent with lack of involvement of XPO1 in TDP-43 export, addition of the XPO1 inhibitor leptomycin B

181 (LMB, $100 \mathrm{nM})$ during the permeabilization, washing, and export phases did not alter TDP-43 nuclear efflux

182 (Suppl fig 3C). Next, we tested the effect of adding ATP and saw no change in the rate of nuclear export

183 at concentrations far exceeding those that support active nuclear transport in permeabilized cell systems

184 (Cassany \& Gerace, 2009; Hayes et al, 2020, 2021) (Suppl fig 3D). To confirm that the data are not

185 confounded by TDP-43 import back into the nucleus, we tested the ability of our permeabilized cell system

186 to support active nuclear import. Although no import receptors or Ran cycle proteins were added to the 187 assay, residual importins do remain at NPCs upon cell permeabilization (Kapinos et al, 2017). Therefore, 188 we analyzed the capacity for nuclear import of Rango, a FRET sensor and direct importin $\beta$ cargo (Kalab et al, 2006; Hayes et al, 2020), and saw no import in our lysate-free conditions, with or without added ATP

190 (Suppl fig 3E). Our findings are therefore unlikely to be confounded by the nuclear re-entry of TDP-43.

191 Taken together, these data demonstrate that TDP-43 nuclear efflux in permeabilized cells is accelerated by

192 heat and 1,6-hexanediol, but not ATP, consistent with nuclear export by passive diffusion through NPC 193 channels. 
196 The observation that TDP-43 exits the nucleus in permeabilized cells under passive conditions, and its exit

197 is not accelerated by ATP, suggests that canonical, energy-requiring RNA export pathways are unlikely to

198 be required for TDP-43 nuclear export. This includes the exportin-family of receptors which rely on the

199 Ran-GTPase gradient (e.g. XPO1, XPOT, and XPO5), and the TREX bulk mRNA export pathway, which is

200 independent of Ran but requires the activity of ATP-dependent RNA helicases, including UAP56 and

201 DDX19b, for mRNP export complex assembly and disassembly (Okamura et al, 2015). In support of this,

202 individual siRNA knockdown of XPO1, XPO5, XPOT, the NXF1 mRNA export receptor, and AlyREF, a

203 TREX complex protein that participates in NXF1-recruitment, did not alter TDP-43 steady-state localization

204 (Archbold et al, 2018; Ederle et al, 2018). Similarly, TDP-43 RRM mutations did not prevent nuclear export

205 in the heterokaryon assay (Ederle et al, 2018). However, XPO1, XPO7, and NXF1 overexpression

206 promoted TDP-43 cytoplasmic redistribution (Archbold et al, 2018). Of note, NXF1 has also been identified

207 as a potential TDP-43 interacting protein (Freibaum et al, 2010).

To further exclude a role for the NXF1/TREX pathway in TDP-43 nuclear export, we utilized a DLD1 cell

210 line in which an auxin-inducible degron (AID) tag was introduced into the endogenous NXF1 locus via

211 CRISPR (Aksenova et al, 2020). TIR1 ligase, which drives ubiquitination of AID-tagged proteins upon

212 auxin-mediated recruitment, was separately integrated at the C-terminus of the nuclear protein RCC1 via a

213 self-cleavable P2A sequence. This enables rapid and complete degradation of the NXF1 protein within $1 \mathrm{~h}$

214 of exposure to $0.5 \mathrm{mM}$ auxin (Fig 3A). Due to TIR1 leakage, DLD1-NXF1-AID cells showed mildly reduced

215 NXF1 expression even prior to auxin administration (Fig 3A asterisk). To examine the effect of NXF1

216 ablation on mRNA export, DLD1-wild-type and DLD1-NXF1-AID cells were treated with auxin for 0-8 h,

217 fixed, and poly(A)-RNA N/C localization was analyzed by fluorescence in situ hybridization (FISH) (Fig 3B-

218 C). DLD1-NXF1-AID cells showed an $\sim 30 \%$ increase in the poly(A)-RNA N/C ratio even prior to auxin

219 administration ( $p<0.05$ vs. DLD1-wild-type), consistent with the reduced NXF1 expression. Auxin induced

220 further, progressive accumulation of nuclear poly $(A)$-RNA to $>300 \%$ of baseline by $8 \mathrm{~h}$, consistent with the

221 inhibition of mRNA export (Fig 3B-C). To determine the effect of NXF1 ablation on transcriptional

222 blockade-induced TDP-43 nuclear export, cells were treated with auxin for 0-8 h, followed by a $2 \mathrm{~h}$

223 incubation \pm NVP-2 prior to fixation and TDP-43 immunostaining (Fig 3D-E). Interestingly, DLD1-NXF1-AID 
224 cells showed an increased steady-state TDP-43 N/C ratio compared to DLD1-wild-type cells that increased

225 with auxin treatment, presumably due to TDP-43 binding to increased nuclear poly(A)-RNA (Fig 3D).

226 However, after adjusting for this increased steady-state N/C ratio, there was no delay in NVP-2-induced

227 TDP-43 nuclear export in DLD1-NXF1-AID cells until 8h, when subtle slowing was observed (Fig 3E).

228 These results suggest that inhibiting mRNA export promotes TDP-43 nuclear accumulation, but the NXF1

229 receptor itself does not mediate TDP-43 export across the NPC.

\section{TDP-43 nuclear localization depends on binding to GU-rich RNAs}

232 Since TDP-43 is primarily nuclear, despite its ability to diffuse through the NPC, we reasoned that TDP-43

233 localization must depend on intranuclear sequestration, perhaps binding to RNA given the rapid nuclear

234 efflux induced by transcriptional inhibition and nuclear accumulation conferred by mRNA export blockade.

235 To test this hypothesis, we added increasing concentrations of RNase A to permeabilized cells and

236 monitored the effect on TDP-43 nuclear localization (Fig 4A-C). In contrast to untreated controls, RNase

237 treatment caused rapid TDP-43 nuclear efflux over 30 minutes even at $4^{\circ} \mathrm{C}$, suggesting that RNA indeed

238 tethers TDP-43 within the nucleus. Interestingly, following RNase treatment, residual endogenous nuclear

239 TDP-43 formed puncta (Fig 4B arrows), as reported following nuclear RNase microinjection in living cells

240 (Maharana et al, 2018), and similar to the expression pattern of tagged, overexpression constructs of TDP-

24143 RNA binding mutants (Ayala et al, 2008; Elden et al, 2010; Wang et al, 2020; Yu et al, 2020).

242 Furthermore, in addition to the temperature-induced changes in the NPC permeability barrier discussed

243 above (Fig. 2D-E), these results suggest that temperature-sensitive dissociation from RNAs contributes to

244 the drastically reduced passive TDP-43 nuclear exit at $4^{\circ} \mathrm{C}$ versus $37^{\circ} \mathrm{C}$. To assess nuclear integrity, we

245 also analyzed the effect of RNase on the nuclear localization of DDX19b (54 kD) and Nup50 (50 kD), two

246 proteins of similar size to TDP-43 that are localized to the NPC and nucleoplasm (Suppl fig 4A). The

247 nuclear intensity of both proteins was unaffected at $4^{\circ} \mathrm{C}$, and modestly diminished at $37^{\circ} \mathrm{C}$, but overall

248 remarkably stable compared to the rapid nuclear efflux observed for TDP-43. The observation of the critical

249 role of RNA in TDP-43 nuclear localization prompted us to test whether RNA degradation post-

250 permeailization contributes to the TDP-43 nuclear efflux we observed in our passive export assay (Suppl

251 fig 4B). We saw no difference in the rate of TDP-43 nuclear efflux in permeabilized cells kept at $37^{\circ} \mathrm{C}$ for 
25230 or 60 min, with or without RNasin, suggesting that RNA degradation does not contribute to the passive

253 export we observe. Nevertheless, RNasin was added to the transport buffer for all permeabilized cell

254 assays as a precautionary measure.

256 CLIP-seq studies demonstrate that TDP-43 preferentially binds repetitive GU-rich sequences, particularly

257 within introns (Polymenidou et al, 2011; Tollervey et al, 2011), and the RRM domains optimally recognize a

258 synthetic 'AUG12' (GUGUGAAUGAAU) motif (Lukavsky et al, 2013). To investigate the specificity of the

259 RNA-mediated nuclear tethering of TDP-43, we added synthetic RNA oligomers designed as 'decoys'

260 mimicking the preferred GU-rich binding sites to the permeabilized cell passive nuclear export system (Fig

261 4D-G). Following permeabilization, increasing concentrations of (GU)8, 'AUG12', or A16 oligomers were

262 introduced, and cells incubated at $4^{\circ} \mathrm{C}$ for $30 \mathrm{~min}$ (Fig 4D). Both 'AUG12' and (GU)8 induced dose-

263 dependent nuclear efflux of TDP-43, presumably by competitive dissociation of TDP-43 from endogenous

264 nuclear RNAs, freeing TDP-43 to passively exit the nucleus. The A16 control oligomer had no effect.

265 Incubating permeabilized cells with (GU)8 at increasing temperatures $\left(25^{\circ} \mathrm{C}\right.$ and $\left.37^{\circ} \mathrm{C}\right)$ markedly

266 accelerated (GU)8-induced TDP-43 export (Fig 4E), consistent with the expected temperature-dependency

267 of TDP-43 free diffusion, NPC permeability, and temperature-sensitive dissociation of TDP-43 from nuclear 268 RNAs.

270 Next, we evaluated the selectivity of the oligomer-induced nuclear efflux comparing different RNA motifs

271 and RBPs in the permeabilized cell system. (GU)8 induced nuclear efflux of TDP-43 but not three other

272 RBPs, including HuR which preferentially recognizes related U-rich motifs (Fig 4F) (e.g. UUGGUUU,

273 http://rbpmap.technion.ac.il/ (Paz et al, 2014; Silanes et al, 2004; Lebedeva et al, 2011)). Conversely,

274 polyU (U20) induced the nuclear efflux of HuR but not TDP-43 or other RBPs (Fig 4G). An oligomer based

275 on the U1 snRNP splice site sequence (CAAAGGUAAGUUGGA (Kondo et al, 2015)) selectively induced the

276 nuclear export of the U1 small nuclear ribonucleoprotein $70 \mathrm{kDa}$ (U1-70K or snRNP70), with no significant effect

277 on the localization of TDP-43, hnRNPA2/B1, or PABPN1. C16 and A16 oligomers failed to induce nuclear

278 export of any RBPs tested, including those predicted to bind (i.e. hnRNPK and PABPN1, respectively (Choi et

279 al, 2009; Goss \& Kleiman, 2013)). Thus, at least in the permeabilized cell system, these results show that 
280 nuclear localization of a subset of RBPs, including TDP-43, depends on remarkably specific and selective 281 binding to their preferred binding motifs within nuclear RNAs.

283 Finally, we tested the ability of RNA oligomers to alter TDP-43 nuclear localization in live cells (Fig $\mathbf{4 H}$ ).

284 HeLa cells were transfected with increasing concentrations of (GU)6 or A13 oligomers that were modified

285 by the addition of 2'-O-methyl groups and phosphorothioate bonds to prevent degradation by cellular

286 RNases. Cells were fixed $5 \mathrm{~h}$ after transfection for immunostaining and analysis. As in permeabilized cells,

287 (GU)6 but not A13 induced dose-dependent TDP-43 nuclear efflux (Fig 4I). Again, this was specific for

288 TDP-43 as there was no change in the N/C ratio of HuR, FUS, or hnRNPA2/B1 (Fig 4J). Together, these

289 findings confirm that in live cells, specific binding to endogenous GU-rich nuclear RNAs opposes the 290 tendency of TDP-43 to passively leave the nucleus.

Inhibition of pre-mRNA splicing promotes TDP-43 nuclear accumulation

293 Since GU-rich nuclear RNA binding appears critical for TDP-43 nuclear retention, we hypothesized that 294 TDP-43 nuclear accumulation relies on the abundance of GU-rich intronic sequences in newly-transcribed 295 pre-mRNAs prior to splicing and degradation of released introns. Since inhibition of pre-mRNA splicing 296 stalls intron excision and leads to nuclear accumulation of unspliced pre-mRNAs (Carvalho et al, 2017), we 297 used two splicing inhibitors, the Ginkgo biloba tree-derived bioflavinoid isoginkgetin (IGK) (O'Brien et al, 298 2008) and the bacterial macrolide pladienolide B (PLB) (Sato et al, 2014), to test whether nuclear intron 299 accumulation could reduce TDP-43 nuclear efflux. PLB binds and inhibits SF3B1 in the U2 snRNP in the 300 first step of spliceosome assembly (Kotake et al, 2007). The precise target of IGK has not yet been 301 identified, but it blocks the complex A to complex B transition during spliceosome assembly, downstream of 302 PLB (O'Brien et al, 2008). After a $4 \mathrm{~h}$ exposure, both IGK and PLB induced accumulation of introns as 303 determined by qRT-PCR analysis with primers targeting the exon/intron junction of selected housekeeping 304 genes, normalized to the expression of U6 snRNA, an unspliced transcript of RNA polymerase III (O'Brien 305 et al, 2008) (Suppl fig 5). Over the same time course, there was a dose-dependent increase in the steady306 state N/C ratio of TDP-43 (Fig 5A-B, D-E). Remarkably, when cells were incubated for $4 \mathrm{~h}$ with IGK or 307 PLB, and NVP-2 was added to induce transcriptional blockade and TDP-43 nuclear efflux, both IGK and 
308 PLB promoted TDP-43 nuclear retention, in a dose-dependent manner (Fig 5C,F). This effect was more

309 potent for IGK than PLB, albeit at higher doses $\left(I G K I C_{50}=62 \mu \mathrm{M}\right.$, PLB IC $\left.I_{50}=6 \mathrm{nM}\right)$. Together with the

310 observed effects of GU-rich oligomers in permeabilized and live cells, these data strongly suggest that

311 TDP-43 nuclear localization depends on the abundance of its nuclear intronic pre-mRNA binding sites.

313 TDP-43 RRM domains confer RNA-dependent TDP-43 nuclear localization

314 The RNA-binding properties of the TDP-43 RRM domains have been extensively characterized (Buratti \&

315 Baralle, 2001; Lukavsky et al, 2013; Cohen et al, 2015; Flores et al, 2019). Although mutation or deletion of

316 the RRM domains does not abolish TDP-43 nuclear localization (Elden et al, 2010; Yu et al, 2020), these

317 observations arise from fluorescently tagged, high molecular weight TDP-43 constructs, which markedly

318 inhibits TDP-43 nuclear export (Suppl fig 1K; Ederle et al, 2018; Pinarbasi et al, 2018). However, Ayala

319 and colleagues previously generated TDP-43 RRM mutants with a small ( 1 kD) FLAG tag and

320 demonstrated increased cytoplasmic localization by N/C fractionation and immunoblotting (Ayala et al,

321 2008). To further assess the role of the RRM domains for TDP-43 nuclear localization and export without

322 markedly increasing its molecular weight, we generated a series of constructs expressing V5-tagged wild-

323 type and RRM mutants of TDP-43 (Fig 6A), including mutations of phenylalanine residues (5F $\rightarrow L)$ and

324 acetylation sites $(2 \mathrm{~K} \rightarrow \mathrm{Q})$ that are critical for RNA binding (Buratti \& Baralle, 2001; Cohen et al, 2015), and

325 a complete RRM deletion ( $\triangle$ RRM1-2). Constructs were transiently transfected into a stable HeLa cell line

326 largely depleted of TDP-43 by CRISPR (Suppl fig 6A-B) (generously provided by S. Ferguson (Roczniak-

327 Ferguson \& Ferguson, 2019)) to avoid potential confounding effects of hetero-oligomerization with

328 endogenous TDP-43. High-content image analysis showed a significant drop in the steady-state N/C ratio

329 of all three RRM mutants, presumably exaggerated for $\Delta R R M 1-2$ due to its small size (29 kD) in

330 comparison to the point mutants (45 kD) (Fig 6A-B). In addition to reduced nuclear accumulation of the

331 RRM mutants, shuttling in response to NVP-2 was abolished. Next, we confirmed these findings with N/C

332 fractionation and immunoblotting (Fig 6C-D). The immunoblotting results corroborated our image-based

333 analyses, showing a marked reduction in the N/C ratio of TDP-43 in all three RRM mutants and no

334 response to NVP-2. Thus, TDP-43 RRM domains are required for nuclear TDP-43 localization and RNA-

335 regulated shuttling behavior. 
337 Of note, coalescence of the V5-tagged RRM mutants into nuclear puncta was only rarely observed, 338 compared to widespread puncta observed in cells transfected with YFP-tagged TDP-43-5F $\rightarrow$ L (Suppl fig

339 6C,F) (Elden et al, 2010). Since 27kD-YFP contains the same three residues (F223, L221, A206) known to 340 cause dimerization of GFP (Day \& Davidson, 2009), the presumed nuclear phase separation behavior of

341 TDP-43 RRM mutants could be exacerbated by the size or dimerization activity of GFP-derived

342 fluorophores that can drive aberrant localization of tagged proteins in live cells (Snapp et al, 2003; Falcón-

343 Pérez et al, 2005). Indeed, we also saw a trend toward increased nuclear puncta formation by wild type

344 TDP-43-YFP compared to TDP-43-V5, though never to the extent of TDP-43-5FL-YFP (Suppl fig 6F).

\section{Role of HSP70 chaperone activity in nuclear/cytoplasmic localization of RNA-free TDP-43}

347 The HSP70 family of chaperones was recently shown to regulate the nuclear phase separation of RNA-free 348 TDP-43 into droplets or "anisosomes" (Yu et al, 2020). We wondered whether, in addition to NLS-mediated 349 nuclear import, HSP70 activity might therefore contribute to the nuclear localization of TDP-43 RRM 350 mutants. First, we confirmed that HSP70 inhibition strongly modifies fluorescent nuclear puncta in TDP-43 351 CRISPR KO cells transiently transfected with TDP-43-YFP or TDP-43-5FL-YFP (Suppl fig 6C). TDP-43352 5FL-YFP-expressing cells exhibited striking and widespread nuclear puncta, observed in $99.8 \%$ of cells vs. $35335 \%$ of wild-type TDP-43-YFP-expressing cells (Suppl fig 6F). Consistent with the report of Yu and 354 colleagues, treatment with the HSP70 small molecule inhibitor VER 155008 (HSP70i, $50 \mu \mathrm{M})$ (Massey et 355 al, 2010; Yu et al, 2020) induced a steady decline in the number of TDP-43-5FL-YFP puncta per nucleus 356 (Suppl fig 6D), whereas no change was seen in TDP-43-YFP-expressing cells. Since the YFP tag alters 357 nuclear localization and export (Suppl fig 1K), next we verified that HSP70 also regulates nuclear puncta 358 formation using our V5-tagged RRM mutants (Suppl fig 6E). As shown in Fig 6, the V5-tagged proteins 359 formed far fewer nuclear puncta, observed in $9 \%$ of WT-V5, $17 \%$ of 2 KQ-V5, $14 \%$ of $5 F L-V 5$, and $13 \%$ of $360 \Delta R R M 1,2-V 5-t r a n s f e c t e d$ cells (Suppl fig 6F). Puncta consisted of fine granules in 2KQ-V5 and 5FL-V5361 expressing cells and larger spherical/shelled structures in the $\Delta R R M 1,2-V 5$-transfected cells (arrows in 362 Suppl fig 6E), and were more likely to be observed in higher-expressing cells across all constructs. 363 HSP70i induced a significant increase in the number of cells with nuclear puncta in both $2 \mathrm{KQ}-\mathrm{V} 5$ and 
ARRM1,2-V5-transfected cells, and a similar trend in 5FL-V5-transfected cells (Suppl fig 6E-F),

365 accompanied by increased mean puncta/nucleus and mean puncta area that was never observed in WT-

366 V5-expressing cells (Suppl fig 6H). Thus, while HSP70i induced the simplification of pre-existing nuclear

367 puncta in TDP43-5FL-YFP-expressing cells, it induced the formation of new and more numerous nuclear

368 puncta in cells expressing V5-RRM mutants with a smaller, dimerization-free tag. Given reduced antibody

369 penetration into densely-packed liquid spherical shells of larger anisosomes (Yu et al, 2020), it is possible

370 that the V5 immunofluorescence (IF) under-represents the amount of V5-TDP-43 residing in nuclear

371 puncta. However, N/C fractionation and immunoblotting (using denaturing conditions) showed a remarkably

372 similar distribution of V5-tagged TDP-43 to the results obtained with IF (Fig 6), indicating that only a small

373 fraction of the total V5-TDP-43 is enclosed in structures invisible by IF. Overall, HSP70i treatment is clearly

374 altering the nuclear distribution of V5-tagged RRM mutants (Suppl fig 6), confirming potent chaperone

375 activity in regulating the sub-nuclear localization of RNA-free TDP-43 in our model system.

Next, we analyzed the effect of HSP70i on the nuclear/cytoplasmic partitioning of TDP-43-V5 versus V5tagged RRM mutants at steady state and following NVP-2-induced transcriptional blockade (Suppl fig 6I). Again, NVP-2 induced cytoplasmic shuttling of wild-type TDP-43-V5 and had no effect on the RRM mutants. Interestingly, HSP70i did not further compromise the ability of RRM-mutant TDP-43 to remain in the nucleus. Rather, HSP70i induced a modest (10-15\%) increase in the TDP-43 N/C ratio of all three RRM mutants that was not observed for wild-type TDP-43-V5. Thus, HSP70-dependent nuclear chaperone activity appears to modestly favor the nuclear export of RNA-free TDP-43, by an unknown mechanism.

These data suggest that HSP70 chaperones do not contribute to the nuclear accumulation of RRM-mutant TDP-43, which is most likely attributable to ongoing active and passive nuclear import.

\section{Discussion}

In this study, we investigated the mechanism of TDP-43 nuclear export and the regulatory role of RNA in maintaining TDP-43 nuclear localization. In permeabilized cells, TDP-43 readily exited the nucleus in low-ATP conditions, consistent with passive diffusion through NPCs. Acute depletion of NXF1 did not alter TDP-43 nuclear export in live cells, further excluding active TDP-43 co-export with mRNA. Three lines of evidence 
392 indicate that binding to GU-rich nuclear RNAs sequesters TDP-43 in nuclei and controls its availability for

393 passive nuclear exit. (1) Degradation of nuclear RNAs by RNase treatment in permeabilized cells induced 394 rapid TDP-43 nuclear efflux, demonstrating that RNA is required for TDP-43 nuclear sequestration. (2) In

395 permeabilized and live cells, synthetic GU-rich oligomers induced nuclear TDP-43 exit, likely by competitive 396 displacement of TDP-43 from endogenous GU-rich nuclear RNAs. Moreover, splicing inhibitors promoted

397 TDP-43 nuclear accumulation and resistance to nuclear efflux upon transcriptional blockade, further

398 supporting the critical role of TDP-43 binding to intronic pre-mRNAs for maintenance of nuclear

399 localization. (3) Mutation or deletion of TDP-43 RRM domains strongly reduced TDP-43 nuclear enrichment

400 and abolished its RNA-regulated shuttling. Taken together, these findings support a model (Fig 7) in which

401 TDP-43 nuclear/cytoplasmic distribution results from a balance between active and passive TDP-43

402 nuclear import, nuclear sequestration by binding to GU-rich intronic pre-mRNAs, and passive nuclear

403 export. In this model, TDP-43 moves in and out of the nucleus via a reaction-diffusion-controlled

404 mechanism (Bastiaens et al, 2006; Soh et al, 2010) whereby transient formation of high molecular weight

405 TDP-43 complexes with nuclear pre-mRNAs ('reaction') locally sequesters TDP-43 within nuclei and

406 hinders availability of free TDP-43 for passive diffusion through NPC channels. Since inhibition of nuclear

407 RNA synthesis and competitive displacement with GU-RNA 'decoys' both induced net TDP-43 nuclear exit

408 in living cells, the active import rate of TDP-43 is clearly insufficient to balance passive export resulting

409 from loss of nuclear pre-mRNA binding sites. Either a drop in nuclear pre-mRNA binding sites or mutation

410 of the TDP-43 RRM domains steeply increases the nuclear abundance of TDP-43 that can passively

411 diffuse through NPCs, leading to (near) equilibration of TDP-43 between the nucleus and cytoplasm. By

412 maintaining the nuclear abundance of GU-rich intronic pre-mRNAs, the dynamic balance of transcription

413 and pre-mRNA processing may ultimately be the primary upstream factor determining TDP-43 nuclear

414 localization under physiological conditions.

416 Transcriptional dependence of RBP nuclear enrichment

417 Consistent with previous studies (Piñol-Roma \& Dreyfuss, 1992; Cáceres et al, 1998; Ayala et al, 2008;

418 Ederle et al, 2018), we observed that transcriptional blockade altered the nuclear-cytoplasmic partitioning of

419 numerous RBPs, ranging from prominent accumulation in the cytoplasm (TDP-43 and HuR) to a nearly two-fold 
420 nuclear increase (hnRNPC). Cytoplasmic-shifting RBPs included those with distinct RNA binding preferences,

421 such as TDP-43 (Polymenidou et al, 2011; Tollervey et al, 2011; Lukavsky et al, 2013), HuR (Lebedeva et 422 al, 2011), and hnRNPA1 (Bruun et al, 2016; Jain et al, 2017), as well as NXF1, which binds RNA in a 423 sequence-independent manner (Tuck \& Tollervey, 2013; Baejen et al, 2014). Similarly, RBPs retained or 424 enriched in nuclei upon transcriptional inhibition included sequence-specific binders such as U2AF65 (Wu 425 et al, 1999; Zorio \& Blumenthal, 1999; Merendino et al, 1999) and the DEAD-box helicase DDX19b which 426 has no sequence requirement (Lin et al, 2018). Thus, the diverse shuttling response of individual RBPs to 427 perturbation of transcription appears to be defined by RBP-specific protein-RNA and protein-protein 428 interactions rather than by a particular RNA motif.

Our mechanistic understanding of RNA synthesis-dependent N/C translocations of RBPs, including the factors 431 mediating RBP nuclear export or retention, remains incomplete (Nakielny \& Dreyfuss, 1999). Several RBP432 specific functional domains have been identified to mediate nucleocytoplasmic shuttling, including the HuR 433 nucleocytoplasmic shuttling (HNS) domain (Fan \& Steitz, 1998), the K nuclear shuttling (KNS) motif of 434 hnRNPK (Michael et al, 1997), the M9 signal required for transportin-mediated nuclear import and 435 transcriptional blockade-induced export of hnRNPA1 (Michael et al, 1995), the nuclear retention signal of 436 hnRNPC (Nakielny \& Dreyfuss, 1996), and the SR domain of SF2 (SRSF1), which confers actinomycin D437 dependent shuttling to other proteins (Cáceres et al, 1998). Here, we demonstrate that the TDP-43 RRM1438 RRM2 domains mediate its transcriptional blockade-induced nuclear efflux and act as a nuclear retention 439 domain via binding nuclear RNAs. Interestingly, a recent study showed that the depletion of cytoplasmic RNAs, 440 via activation of the primarily cytoplasmic Xrn1 exonuclease-dependent mRNA decay, induced nuclear 441 translocation of many RBPs, including the cytoplasmic poly(A) binding protein PABPC (Gilbertson et al, 2018). 442 In a spatial inverse to our current model of TDP-43 shuttling, the findings of Gilbertson and colleagues suggest 443 that the cytoplasmic abundance of poly(A)-RNAs may be responsible for maintaining cytoplasmic PABPC 444 localization. Nucleocytoplasmic gradients of the preferred RNA binding motifs may therefore represent a 445 broadly-applicable model for regulating RBP localization, which warrants further investigation. 
448 The FG permeability barrier of the NPC does not have a strict size cutoff; rather, diffusion of cargoes through

449 the NPC is increasingly restricted over the 30-60 kD range (Mohr et al, 2009; Timney et al, 2016). Thus, $43 \mathrm{kD}$

450 TDP-43 monomers are predicted to diffuse across the NPC with moderate efficiency. Indeed, we observed

451 TDP-43 nuclear efflux in permeabilized cells in low-ATP conditions, that was accelerated by NPC

452 permeabilization as expected for passive diffusion from the nucleus. These data corroborate predictions from

453 live-cell assays showing marked size-restriction of TDP-43 nuclear export, including slowed TDP-43-tdTomato

$454(+54 \mathrm{kD})$ export in the heterokaryon assay (Pinarbasi et al, 2018), lack of TDP-43-GCR $-\mathrm{EGFP}_{2}(+119 \mathrm{kD})$

455 cytoplasmic recovery in a dexamethasone-induced shuttling assay (Ederle et al, 2018), and failure of TDP-43-

456 YFP (+27 kD) nuclear efflux following transcriptional blockade (Suppl fig 1K). Delay in active nuclear import

457 has been demonstrated for very large cargos (Paci et al, 2020), and the rate of active mRNP export is

458 modestly size-dependent (Grünwald et al, 2011). However, the exquisite size-limitation of TDP-43 nuclear

459 export in live-cell assays is most consistent with passive diffusion from the nucleus, as our permeabilized cell

460 passive export assay confirms.

462 In addition to size, cargo surface properties also critically dictate NPC passage, including hydrophobic residues 463 which augment NPC transport (Frey et al, 2018). Besides the glycine-rich C-terminal IDR, hydrophobic patches 464 are present throughout the TDP-43 sequence (https://web.expasy.org/protscale/ (Gasteiger et al, 2005)), 465 including within the N-terminal domain, RRM1, and RRM2, but their roles in NPC passage are not known. A 466 recent study showed that intrinsically disordered proteins (up to $\sim 63 \mathrm{kDa}$ ) can passively transit through NPC 467 channels (Junod et al, 2020), suggesting that the disordered state of the TDP-43 C-terminal IDR could 468 potentially contribute to its passive nuclear exit. The potential role of TDP-43 hydrophobic and disordered 469 regions for passive translocation through NPC channels remains to be examined.

\section{Nuclear-cytoplasmic GU-rich RNA gradients and TDP-43 shuttling}

472 CLIP-seq studies have shown that TDP-43 preferably binds to long stretches of GU-rich intronic pre-mRNA 473 sequences present in about $30 \%$ of genes (Polymenidou et al, 2011; Tollervey et al, 2011). Introns are in 474 average much longer than exons in the predicted pre-mRNAs of human genes (7.5 kB vs 320 B (Lee \& Rio, 475 2015)), and some are retained in exported mRNAs due to alternative splicing or incomplete debranching, and 
476 detectable in the cytoplasm as stable intron lariats (Talhouarne \& Gall, 2018; Saini et al, 2019). However, a

477 substantial proportion of nuclear intronic sequences, whether still contained in pre-mRNAs or excised, are likely

478 short-lived, due to the tight coupling of transcription with pre-mRNA splicing, pre-mRNA quality surveillance, and

479 rapid degradation via the nuclear exosome (Lee \& Rio, 2015; Kilchert et al, 2016; Bresson \& Tollervey,

480 2018). Active transcription could then potentially give rise to the $\mathrm{N} / \mathrm{C}$ concentration gradient of the preferred

481 TDP-43 binding sites in intronic GU-rich RNAs. The evident nuclear accumulation of newly-synthesized 5-EU-

482 labeled RNAs in HeLa and neurons (Fig 1A and Suppl fig 1A,F) is indeed consistent with the existence of a

483 steep N/C gradient of U-rich nascent RNAs. Recent rapid advances in CLIP-seq and related methods (Wheeler

484 et al, 2018; Hafner et al, 2021) have yielded detailed insights into the RNA-RBP interactions and their

485 dynamics (Nostrand et al, 2020). Despite this progress, currently available computational methods are not well

486 suited for global quantification of particular sequence motifs (such as GU repeats) across all RNA sequences,

487 although quantitative comparisons within narrowly defined sequence windows are feasible (Boswell et al,

488 2017). Thus, direct quantification of the putative N/C gradient of TDP-43 RNA binding sites might require

489 development of new methodological approaches.

491 Biophysical regulation of TDP-43-RNA binding

492 We observed a drastic reduction in TDP-43 passive nuclear exit from permeabilized cell nuclei at $4^{\circ} \mathrm{C}$ (Fig $2 \mathrm{~B}-$

493 C), far beyond the approximately two-fold decrease in the passive nuclear import of ERK2-GFP at $4^{\circ} \mathrm{C}$ in a

494 similar permeabilized cell system (Whitehurst et al, 2002), Thus, temperature-dependence of free diffusion

495 alone is unlikely to fully account for the slowing we observed at $4^{\circ} \mathrm{C}$. The ability of 1,6 -hexanediol to elicit TDP-

49643 efflux at $4^{\circ} \mathrm{C}$ (Fig 2D-E) suggests that the FG-repeat permeability barrier is temperature-sensitive and likely

497 contributes to the hindrance of TDP-43 passive export at $4^{\circ} \mathrm{C}$. Interestingly, TDP-43 nuclear efflux induced by

498 RNA degradation or GU-rich oligomers was also delayed at $4^{\circ} \mathrm{C}$, suggesting temperature sensitivity of TDP-43

499 - RNA binding, which remains to be experimentally verified. RNA-protein interactions generally involve dynamic

500 rearrangements of both binding partners and their stabilization in the complex (Corley et al, 2020), suggesting

501 that increased mobility of the complex at a higher temperature may promote TDP-43—RNA dissociation.

502 Consistent with this explanation, molecular dynamics and structural studies indicate that van der Waals forces

503 support the majority of the TDP-43-RNA interaction (Sun et al, 2021) as well as the intramolecular 
504 interactions of RRM1—RRM2, which have a significant influence on TDP-43—RNA affinity (Lukavsky et al,

505 2013). Since van der Waals forces steeply decline with distance of the interacting atoms, a temperature-

506 dependent increase in molecular fluctuation thus could stochastically promote TDP-43 unbinding from nuclear

507 RNAs at $37^{\circ} \mathrm{C}$.

509 The repertoire of TDP-43 GU-rich RNA binding partners identified by CLIP-seq is structurally diverse

510 (Polymenidou et al, 2011; Tollervey et al, 2011), and in vitro measurements show that TDP-43 binds to

511 different GU-rich RNAs with widely ranging dissociation constants ( 3-3000 nM), with the affinity increasing with

512 the number of perfect GU repeats (Bhardwaj et al, 2013). The existence of multiple low affinity-binding sites

513 might have a physiological role in TDP-43 auto-regulation (Avendaño-Vázquez et al, 2012; Bhardwaj et al,

514 2013) and helps to explain the ability of short GU-rich oligomers, which bind TDP-43 in vitro with low-nM affinity

515 (Bhardwaj et al, 2013; French et al, 2019), to displace TDP-43 from endogenous RNAs (Fig 4D,I). Although

516 RNase caused a near-complete evacuation of TDP-43 from nuclei in permeabilized cells (Fig 4B-C), TDP-43

517 efflux induced by transcriptional blockade (Fig 1C, Suppl Fig 1C,H,J) and GU-rich 'decoy' oligomers (Fig 4I)

518 showed a time- and dose-dependent plateau in living cells. In addition to ongoing active nuclear import, the

519 existence of an 'export-resistant' nuclear pool of TDP-43 may result from its binding to other nuclear RNAs such

520 as long non-coding RNAs, which constitute a subset of TDP-43 RNA binding partners (Polymenidou et al,

5212011 ; Tollervey et al, 2011) and have been shown to play a role in TDP-43 nuclear LLPS (NEAT 1) (Wang et

522 al, 2020) and nuclear localization (Malat1) (Nguyen et al, 2019). 'Export-resistant' TDP-43 may also represent

523 TDP-43 bound to chromatin or nuclear matrix constituents, as supported by TDP-43 chromatin fractionation

524 data (Ayala et al, 2008). Since TDP-43 preferentially binds ssDNA (Buratti \& Baralle, 2001), direct binding to

525 genomic DNA is uncertain, but TDP-43 could be indirectly associated with chromatin via protein-protein

526 interactions with histones or other chromatin-associated proteins (Freibaum et al, 2010). Indeed, TDP-43 was

527 identified among numerous chromatin-associated RBPs in a recent crosslinking/co-precipitation analysis

528 (Rafiee et al, 2021). Nevertheless, a large fraction of endogenous, wild-type TDP-43 in our model systems

529 exhibited nuclear RNA concentration-dependent shuttling. 
532 Together with NLS-mediated active nuclear import, our results indicate that TDP-43 RRM1,2-dependent pre-

533 mRNA-binding plays a critical role in establishing the steep concentration gradient of TDP-43 across the nuclear

534 envelope (Fig 6). Multiple additional physiologic and pathologic processes likely function in parallel to modulate

535 TDP-43 steady-state localization and availability for active or passive nucleocytoplasmic transport. These

536 include oligomerization (Mompeán et al, 2017; Afroz et al, 2017; French et al, 2019), LLPS (Molliex et al,

537 2015; Conicella et al, 2016; Zacco et al, 2018; Mann et al, 2019; Conicella et al, 2020; Carter et al, 2021),

538 alternative splicing to truncated isoforms (Weskamp et al, 2020), post-translational modifications, such as

539 phosphorylation, ubiquitination, SUMOylation, acetylation, and C-terminal cleavage (Prasad et al, 2019;

540 François-Moutal et al, 2019), and pathologic aggregation in disease (Arai et al, 2006; Neumann et al, 2006).

541 Aberrant maturation of TDP-43 LLPS condensates by seeding (Gasset-Rosa et al, 2019) or optogenetic

542 clustering (Mann et al, 2019) has been shown to progressively divert the soluble TDP-43 pool into insoluble,

543 high molecular weight cytoplasmic aggregates that seemingly become irreversibly unavailable for nuclear

544 transport. Interestingly, GU-RNA oligomers attenuate recombinant TDP-43 aggregation in vitro (French et al,

545 2019) and optogenetically-induced cytoplasmic TDP-43 aggregation in living cells (Mann et al, 2019),

546 consistent with the notion that access to GU-rich RNAs promotes TDP-43 availability for nucleocytoplasmic

547 shuttling.

\section{Disruption of RNA metabolism in ALS/FTD}

The observation that GU-rich nuclear pre-mRNAs critically regulate TDP-43 nuclear localization raises the

552 Indeed, disruption of RNA processing and RNA-based therapy development are of growing interest in the

553 neurodegenerative disease field (Nussbacher et al, 2019; Butti \& Patten, 2019; Zaepfel \& Rothstein, 2021).

554 The status of the GU-rich RNA gradient in TDP-43-mislocalized cells in ALS/FTD is unknown, and few studies

555 to date have examined factors predicted to alter the availability of nuclear GU-rich pre-mRNA binding sites,

556 such as transcription and splicing dynamics or nuclear RNA turnover. However, analysis of genome-wide RNA

557 stability in fibroblasts and induced pluripotent stem cells using metabolic labeling (Bru-seq) demonstrated RNA

558 destabilization in ALS patient-derived cells versus controls (Tank et al, 2018). Spliceosomal machinery has

559 also appeared as a common denominator in both knockout and interactome analyses of RBPs implicated in 
560 familial ALS/FTD (Chi et al, 2018a, 2018b). Further investigation of these factors is warranted as well as N/C

561 transcriptome compartmentalization, which has shown changes in nuclear RNA retention in the context of

562 neuropsychiatric disoders (Price et al, 2019), and may provide clues as to perturbation of RNA processing in

563 ALS/FTD. Based on the similar behavior of TDP-43 in HeLa cells and neurons following transcriptional inhibition

564 (Fig 1 and Suppl fig 1), it appears likely that the RNA-based regulation of TDP-43 nuclear localization is

565 conserved across somatic and neuronal cells. Moreover, it is tempting to speculate that neuron-specific

566 perturbations in RNA processing/metabolism (Mauger et al, 2016; Hermey et al, 2017; Jaffrey \& Wilkinson,

567 2018; Furlanis et al, 2019; Saini et al., 2019; Tyssowski \& Gray, 2019; Ling et al, 2020) may contribute to

568 cell-specific TDP-43 mislocalization in disease.

Conclusion

571 In summary, nuclear GU-RNA binding and abundance regulate TDP-43 steady-state nuclear localization by

572 dictating availability for passive nuclear export. Further investigation is needed to determine if disruption of RNA

573 metabolism or localization contribute to TDP-43 nuclear clearance in ALS/FTD. Our findings also suggest that

574 RNA-based approaches may be a useful strategy to restore TDP-43 nuclear localization and attenuate TDP-43

575 nuclear loss of function defects in disease.

Methods

\begin{tabular}{|l|l|l|}
\hline Reagent/Resource & Reference or Source & Identifier or Catalog No. \\
\hline Experimental Models & & \\
\hline HeLa cells (human) & ATCC and (Kalab et al, 2006) & HeLa clone 61 \\
\hline $\begin{array}{l}\text { TDP-43 CRISPR KO HeLa cells } \\
\text { human) }\end{array}$ & $\begin{array}{l}\text { (Roczniak-Ferguson \& Ferguson, } \\
2019)\end{array}$ & \\
\hline HEK293T cells (human) & ATCC & \\
\hline DLD1-wildtype cells (human) & ATCC and (Aksenova et al, 2020) & \\
\hline DLD1-NXF1-AID cells (human) & ATCC and (Aksenova et al, 2020) & \\
\hline Mouse primary cortical neurons & $\begin{array}{l}\text { E16 timed pregnant mice } \\
\text { (Jackson laboratory) }\end{array}$ & \\
\hline Recombinant DNA & & \\
\hline $\begin{array}{l}\text { V5-tagged TDP-43 expression } \\
\text { constructs }\end{array}$ & This study & See Table 1 \\
\hline pcDNA3.2 TDP-43 YFP & (Elden et al, 2010) via Addgene & Cat \#84911 \\
\hline pcDNA3.2 TDP-43 5F-L YFP & (Elden et al, 2010) via Addgene & Cat \#84914 \\
\hline
\end{tabular}




\begin{tabular}{|c|c|c|}
\hline pRSET Rango-2/a1+linkers & (Hayes et al, 2020) & pK44 \\
\hline Importin $\beta$ (71-876) & (Drutovic et al, 2020) & pKW488 \\
\hline \multicolumn{3}{|l|}{ Antibodies } \\
\hline $\begin{array}{l}\text { Mouse anti-TDP43 monoclonal } \\
\text { (WB: } 1: 2000, \text { IF: } 1: 2000-1: 5000 \text { ) }\end{array}$ & Abcam [3H8] & Cat\# ab104223 \\
\hline $\begin{array}{l}\text { Rabbit anti-hnRNP A1 polyclonal } \\
\text { (IF: 1:2000) }\end{array}$ & Proteintech & Cat\# 11176-1-AP \\
\hline $\begin{array}{l}\text { Mouse anti-hnRNP A2/B1 } \\
\text { monoclonal (IF: 1:50) }\end{array}$ & Santa Cruz Biotechnology & Cat\# sc-53531 \\
\hline $\begin{array}{l}\text { Rabbit anti-hnRNP A2/B1 } \\
\text { polyclonal (IF: 1:1000) }\end{array}$ & Invitrogen & Cat\#PA5-30061 \\
\hline $\begin{array}{l}\text { Mouse anti-hnRNP C1/C2 } \\
\text { monoclonal (IF: } 1: 100)\end{array}$ & Santa Cruz Biotechnology & Cat\# sc-32308 \\
\hline $\begin{array}{l}\text { Rabbit anti-hnRNP F polyclonal } \\
\text { (IF 1:500) }\end{array}$ & Thermo Scientific & Cat\# PA5-22341 \\
\hline $\begin{array}{l}\text { Mouse anti-hnRNP K monoclonal } \\
\text { (IF: 1:100) }\end{array}$ & Santa Cruz Biotechnology & Cat\# sc-28380 \\
\hline $\begin{array}{l}\text { Rabbit anti-hnRNP M polyclonal } \\
\text { (IF: 1:500) }\end{array}$ & Thermo Scientific & Cat\# PA5-30247 \\
\hline $\begin{array}{l}\text { Rabbit anti-FUS polyclonal } \\
(\text { IF: } 1: 3000)\end{array}$ & Bethyl & Cat\# A300-302A \\
\hline $\begin{array}{l}\text { Rabbit anti-PABPN1 monoclonal } \\
\text { (IF: 1:1000) }\end{array}$ & Invitrogen & Cat\# MA5-32621 \\
\hline $\begin{array}{l}\text { Rabbit anti-PCBP1 polyclonal } \\
\text { (IF: 1:500) }\end{array}$ & Invitrogen & Cat\# PA5-65369 \\
\hline $\begin{array}{l}\text { Rabbit anti-Matrin } 3 \text { monoclonal } \\
\text { (IF 1:1000) }\end{array}$ & Abcam & Cat\# ab151714 \\
\hline $\begin{array}{l}\text { Mouse anti-AlyREF monoclonal } \\
\text { (IF: } 1: 500)\end{array}$ & Santa Cruz Biotechnology & Cat\# sc-32311 \\
\hline $\begin{array}{l}\text { Rabbit anti-Nup50 monoclonal } \\
\text { (IF: 1:250) }\end{array}$ & Abcam & Cat\# ab137092 \\
\hline $\begin{array}{l}\text { Rabbit anti-DDX19b polyclonal } \\
\text { (IF: } 1: 3000)\end{array}$ & Abcam & Cat\# ab151478 \\
\hline $\begin{array}{l}\text { Rabbit anti-NXF1 monoclonal } \\
\text { (IF 1:2000, WB: } 1: 2000)\end{array}$ & Abcam & Cat\# ab129160 \\
\hline $\begin{array}{l}\text { Rabbit anti-ELAVL1/HuR } \\
\text { monoclonal (IF: } 1: 100)\end{array}$ & Cell Signaling Technology & Cat\# 12582 \\
\hline $\begin{array}{l}\text { Mouse anti-DEK monoclonal } \\
\text { (IF: } 1: 100)\end{array}$ & Santa Cruz Biotechnology & Cat\# sc-136222 \\
\hline $\begin{array}{l}\text { Mouse anti-Y14 monoclonal } \\
\text { (IF 1:100) }\end{array}$ & Santa Cruz Biotechnology & Cat\# sc-32312 \\
\hline $\begin{array}{l}\text { Mouse anti-sc35 monoclonal } \\
\text { (IF 1:2000) }\end{array}$ & Sigma-Aldrich & Cat\# S4045 \\
\hline Mouse anti-U1-70K monoclonal & Sigma-Aldrich & Cat\# 05-1588 \\
\hline
\end{tabular}




\begin{tabular}{|c|c|c|}
\hline (IF 1:500) & & \\
\hline $\begin{array}{l}\text { Mouse anti-U2AF65 } \\
\text { (IF 1:100) }\end{array}$ & Santa Cruz Biotechnology & Cat\# 53942 \\
\hline $\begin{array}{l}\text { Mouse anti-UAP56 (BAT1) } \\
\text { monoclonal (IF 1:50) }\end{array}$ & Santa Cruz Biotechnology & Cat\# sc-271395 \\
\hline $\begin{array}{l}\text { Rabbit anti-DHX15 polyclonal } \\
\text { (IF 1:200) }\end{array}$ & Thermo Fisher & Cat\# PA5-561413 \\
\hline $\begin{array}{l}\text { Rabbit anti-FMRP polyclonal } \\
\text { (IF 1:500) }\end{array}$ & Abcam & Cat\# ab17722 \\
\hline $\begin{array}{l}\text { Rabbit anti-GAPDH monoclonal } \\
\text { (WB: } 1: 3000 \text { ) }\end{array}$ & Cell Signaling Technology & Cat\# 5174 \\
\hline $\begin{array}{l}\text { Rabbit anti-V5 monoclonal (WB: } \\
1: 1000, \text { IF 1:2000) }\end{array}$ & Cell Signaling Technology & Cat\# 13202 \\
\hline $\begin{array}{l}\text { Rabbit anti-Lamin B1 polyclonal } \\
\text { (WB: } 1: 1000 \text { ) }\end{array}$ & Abcam & Cat\# ab16048 \\
\hline $\begin{array}{l}\text { Goat anti-mouse IgG AF488 } \\
\text { polyclonal (IF: } 1: 1000)\end{array}$ & Invitrogen & Cat\# A32723 \\
\hline $\begin{array}{l}\text { Goat anti-rabbit IgG AF488 } \\
\text { polyclonal (IF: } 1: 1000)\end{array}$ & Invitrogen & Cat\# A32731 \\
\hline $\begin{array}{l}\text { Goat anti-mouse lgG AF647 } \\
\text { polyclonal (IF: } 1: 1000)\end{array}$ & Invitrogen & Cat\# A32728 \\
\hline $\begin{array}{l}\text { Horse anti-mouse IgG HRP- } \\
\text { conjugated polyclonal (WB: } \\
1: 5000)\end{array}$ & Cell Signaling Technology & Cat\# 7076S \\
\hline $\begin{array}{l}\text { Goat anti-rabbit IgG HRP- } \\
\text { conjugated polyclonal (WB: } \\
1: 5000 \text { ) }\end{array}$ & Cell Signaling Technology & Cat\# 7074S \\
\hline \multicolumn{3}{|l|}{$\begin{array}{l}\text { Oligonucleotides and other } \\
\text { sequence-based reagents }\end{array}$} \\
\hline RNA oligonucleotides & This study & See Table 2 \\
\hline Cy3-oligo-dT(45) & IDT & \\
\hline TDP-43 Taqman assay & ThermoFisher & Cat\# Hs00429203_gH \\
\hline GAPDH Taqman assay & ThermoFisher & Cat\# Hs02786624_g1 \\
\hline \multicolumn{3}{|l|}{ qPCR primers: } \\
\hline$\beta$-tubulin intron 2 forward & $\begin{array}{l}\text { CTATAAACCTTCCCTTCTGCCA } \\
\text { G }\end{array}$ & (Kaida et al, 2007) \\
\hline$\beta$-tubulin exon 4 reverse & $\begin{array}{l}\text { CAGGGTATTCTTCTCGCATCTT } \\
\text { GCTG }\end{array}$ & (Kaida et al, 2007) \\
\hline Actin exon 3 forward & $\begin{array}{l}\text { GGTGGGCATGGGTCAGAAGGA } \\
\mathrm{T}\end{array}$ & (Kaida et al, 2007) \\
\hline Actin intron 4 reverse & $\begin{array}{l}\text { GGAAATGAGGGCAGGACTTAG } \\
\text { CTT }\end{array}$ & (Kaida et al, 2007) \\
\hline DNAJB1 intron 2 forward & $\begin{array}{l}\text { GGCCTGATGGGTCTTATCTATG } \\
\text { G }\end{array}$ & (Kotake et al, 2007) \\
\hline DNAJB1 exon 3 reverse & $\begin{array}{l}\text { AATGAGGTCCCCACGTTTCTCG } \\
\text { GGTGT }\end{array}$ & (Kotake et al, 2007) \\
\hline
\end{tabular}




\begin{tabular}{|c|c|c|}
\hline U6 forward & CGCTTCGGCAGCACATATAC & (O'Brien et al, 2008) \\
\hline U6 reverse & GAATTTGCGTGTCATCCTTG & (O'Brien et al, 2008) \\
\hline \multicolumn{3}{|l|}{$\begin{array}{l}\text { Chemicals, Enzymes and other } \\
\text { reagents }\end{array}$} \\
\hline $\begin{array}{l}\text { Recombinant RNasin } \\
\text { Ribonuclease Inhibitor }\end{array}$ & Promega & Cat\# N2515 \\
\hline RNase A & ThermoFisher & Cat\# EN0531 \\
\hline Digitonin, high purity & Calbiochem & Cat\# 300410 \\
\hline Halt protease inhibitor cocktail & ThermoFisher & Cat\# 78439 \\
\hline $\begin{array}{l}\text { Dextran, Texas Red, } 70,000 \text { MW, } \\
\text { Lysine Fixable }\end{array}$ & Invitrogen & Cat\# D1864 \\
\hline 1,6-Hexanediol & Sigma-Aldrich & Cat\# 240117 \\
\hline ATP disodium salt hydrate & Sigma-Aldrich & Cat\# A6419 \\
\hline $\begin{array}{l}\text { Paraformaldehyde } 32 \% \text { aqueous } \\
\text { solution }\end{array}$ & Electron Microscopy Sciences & Cat\# 15714S \\
\hline HEPES buffer solution & Sigma-Aldrich & Cat\# 83264 \\
\hline 4X Laemmli Sample Buffer & Bio-Rad & Cat\# 1610747 \\
\hline $\begin{array}{l}\text { Blotting Grade Blocker Non-Fat } \\
\text { Dry Milk }\end{array}$ & Bio-Rad & Cat\# 1706404XTU \\
\hline 10x Tris/Glycine/SDS Buffer & Bio-Rad & Cat\# 1610732 \\
\hline Phosphate Buffered Saline & Gibco & Cat\# 10010023 \\
\hline UltraPure Glycerol & Invitrogen & Cat\# 15514011 \\
\hline Hoechst 33342 & Thermo Fisher & Cat\# H1399 \\
\hline Actinomycin D & Sigma-Aldrich & Cat\# A9415 \\
\hline NVP-2 & Tocris Bioscience & Cat\# 6535 \\
\hline 5-ethynyl-uridine & Click Chemistry Tools & Cat\# 1261 \\
\hline Click-\&-Go Cell Reaction Buffer kit & Click Chemistry Tools & Cat\# 1263 \\
\hline Isoginkgetin & Millipore Sigma & Cat\# 416154 \\
\hline Pladienolide B & Cayman Chemicals & Cat\# 13568 \\
\hline Auxin (3-indoleacetic acid) & Sigma-Aldrich & Cat\# I2886 \\
\hline VER 155008 (HSP70i) & ApexBio & Cat\# A4387 \\
\hline Leptomycin B & Cayman Chemicals & Cat\# 10004976 \\
\hline Glass-bottom 96-well plates & CellVis & Cat\# P96-1.5H-N \\
\hline $\begin{array}{l}\text { 4-20\% Criterion TGX Stain-Free } \\
\text { Protein Gel, } 26 \text { well, } 15 \mu \mathrm{l}\end{array}$ & Bio-Rad & Cat\# 5678095 \\
\hline $\begin{array}{l}\text { Trans-Blot Turbo RTA Midi } 0.2 \mu \mathrm{m} \\
\text { Nitrocellulose Transfer Kit }\end{array}$ & Bio-Rad & Cat\# 1704271 \\
\hline $\begin{array}{l}\text { SuperSignal West Pico PLUS } \\
\text { Chemiluminescent Substrate }\end{array}$ & ThermoFisher & Cat\# 34580 \\
\hline $\begin{array}{l}\text { Lipofectamine RNAiMAX } \\
\text { Transfection Reagent }\end{array}$ & Invitrogen & Cat\# 13778030 \\
\hline $\begin{array}{l}\text { NE-PER Nuclear and Cytoplasmic } \\
\text { Extraction Reagents }\end{array}$ & ThermoFisher & Cat\# 78833 \\
\hline
\end{tabular}




\begin{tabular}{|l|l|l|}
\hline $\begin{array}{l}\text { Opti-MEM I Reduced Serum } \\
\text { Medium }\end{array}$ & Gibco/ThermoFisher & Cat\# 31985088 \\
\hline DMEM, high glucose, pyruvate & Gibco/ThermoFisher & Cat\# 11995073 \\
\hline Penicillin-streptomycin 100X & Gibco/ThermoFisher & Cat\# 15140122 \\
\hline Matrigel & Corning & Cat\# 354230 \\
\hline Normal Goat Serum & Vector Labs & Cat\# S-1000 \\
\hline TRIzol & Invitrogen & Cat\# 15596018 \\
\hline $\begin{array}{l}\text { High-Capacity cDNA Reverse } \\
\text { Transcription Kit }\end{array}$ & ThermoFisher & Cat\# 4368814 \\
\hline $\begin{array}{l}\text { PowerSYBR Green PCR Master } \\
\text { Mix }\end{array}$ & ThermoFisher & Cat\# 4367659 \\
\hline CellTiter-Glo 2.0 assay kit & Promega & Cat\# G9242 \\
\hline & & \\
\hline Software & & \\
\hline MetaXpress (v6.1.0.2071) & Molecular Devices & \\
\hline ImageQuant TL (v7.0) & GE Healthcare & \\
\hline Prism (v9.2.0) & Graphpad & \\
\hline FIJI/Image J (v2.1.0/1.53c) & NIH & \\
\hline Photoshop 2021 (v22.4.3) & Adobe & \\
\hline & & \\
\hline Other & & \\
\hline $\begin{array}{l}\text { ImageXpress Micro Confocal } \\
\text { System }\end{array}$ & Molecular Devices & \\
\hline Trans-Blot Turbo Transfer System & Bio-Rad & \\
\hline Nano-drop 1000 & Thermo Scientific & \\
\hline $\begin{array}{l}\text { QuantStudio 3 Real-Time PCR } \\
\text { System }\end{array}$ & ThermoFisher & \\
\hline ImageQuant LAS 4000 System & GE Healthcare & \\
\hline Spectramax M3 plate reader & Molecular Devices & \\
\hline & & \\
\hline
\end{tabular}

579 Immortalized cell culture

580 A single cell-derived clone of HeLa cells (ATCC) was maintained in OptiMEM (Gibco/ThermoFisher) with

$5814 \%$ FBS and penicillin-streptomycin. HEK293T cells (ATCC) and a monoclonal TDP-43 CRISPR-depleted

582 HeLa cell line (a generous gift from Shawn Ferguson (Roczniak-Ferguson \& Ferguson, 2019)), were

583 maintained in DMEM (Gibco/ThermoFisher) with 10\% FBS and penicillin-streptomycin. DLD1-wildtype cells

584 (ATCC) and DLD1-NXF1-AID cells (Aksenova et al., 2020) were maintained in DMEM

585 (Gibco/ThermoFisher) with 10\% FBS and penicillin-streptomycin. All cell lines were validated by STR

586 profiling, routinely verified to be mycoplasma negative, and frequently refreshed from frozen stocks. 
Mouse primary cortical neuron culture

589 All animal procedures were approved by the Johns Hopkins Animal Care and Use Committee. Timed

590 pregnant C57BL/6J females (Jackson Laboratory) were sacrificed by cervical dislocation at E16, cortex

591 dissociated, and cells plated at 50,000/well on poly-D-lysine/laminin-coated, optical glass-bottom 96-well

592 plates as described (Hayes et al, 2020, 2021). Growth medium consisted of Neurobasal supplemented with

593 B27, Glutamax, and penicillin/streptomycin (Gibco/ThermoFisher).

\section{Cloning of recombinant constructs}

Plasmids for the expression of wild-type (WT) human TDP-43 and its variants in tissue culture cells (Table

1) were prepared by Twist Biosciences via gene synthesis between the HindIII and Nhel sites in the

Sanger sequencing.

Table 1. TDP-43 constructs

\begin{tabular}{|l|l|l|l|l|}
\hline Expressed protein & $\begin{array}{l}\text { TDP-43 amino } \\
\text { acids }\end{array}$ & Point mutations & $\begin{array}{l}\text { Predicted } \\
\text { size (kD) }\end{array}$ & ID \# \\
\hline WT TDP-43-V5 & $1-414$ & none & 44.7 & pK1194 \\
\hline $\begin{array}{l}\text { TDP-43 } \\
(\triangle \mathrm{RRM} 1,2)-V 5\end{array}$ & $1-105 ; 260-414$ & none & 28.9 & pK1195 \\
\hline TDP-43 (2KQ)-V5 & $1-414$ & K145Q, K192Q & 44.7 & pK1196 \\
\hline TDP-43 (5FL)-V5 & $1-414$ & F147L, F149L,F194L,F229L,F231L & 44.7 & pK1197 \\
\hline
\end{tabular}

\section{RNA oligonucleotides}

604 Synthetic RNA oligonucleotides (Table 2) were obtained from IDT in the form of desalted lyophilized powder.

\section{Table 2. RNA oligonucleotides}

\begin{tabular}{|l|l|l|l|}
\hline Oligo & $\begin{array}{l}\text { RNA sequence with modifications } \\
\text { m: 2-O-methyl } \\
{ }^{*} \mathrm{~N}: \text { phosporothioate backbone }\end{array}$ & $\begin{array}{l}\text { Assay } \\
\text { PC: permeabilized cells } \\
\text { LC: live cells }\end{array}$ & ID \# \\
\hline (GU)8 & $\mathrm{mG}^{*} \mathrm{UGUGUGUGUGUGUGU}$ & PC & RK6 \\
\hline 'AUG12' & $\mathrm{mA}^{*} \mathrm{mG}^{*} \mathrm{mU}{ }^{*} \mathrm{GmUmGmAmAmUmG} \mathrm{mA}^{*} \mathrm{~mA}^{*} \mathrm{mU}$ & $\mathrm{PC}$ & $\mathrm{RK} 41$ \\
\hline
\end{tabular}




\begin{tabular}{|l|l|l|l|}
\hline U20 & UUUUUUUUUUUUUUUUUUUU & PC & RK32 \\
\hline $\begin{array}{l}\text { U1 snRNP } \\
\text { splice site }\end{array}$ & CAAAGGUAAGUUGGA & PC & RK25 \\
\hline C16 & CCCCCCCCCCCCCCCC & PC & RK3 \\
\hline A16 & AAAAAAAAAAAAAAA & PC & RK37 \\
\hline$(G U) 6$ & $\mathrm{mG}^{*} \mathrm{mU}^{*} m \mathrm{G}^{*} m U^{*} m \mathrm{~m}^{*} \mathrm{mU}^{*} \mathrm{mG}^{*} \mathrm{mU}^{*} \mathrm{mG}^{*} \mathrm{mU}^{*} \mathrm{mG}^{*} U$ & LC & RK7 \\
\hline A13 & $\mathrm{mA}^{*} m A^{*} m A^{*} m A A m A A m A \mathrm{~mA}^{*} m A^{*} \mathrm{~mA}^{*} \mathrm{~mA}$ & LC & RK13 \\
\hline
\end{tabular}

\section{Permeabilized cell TDP-43 export assays}

610 HeLa cells were plated on Matrigel-coated optical glass-bottom 96 well plates (CellVis), at 12,000-15,000 cells 611 per well targeting $80-90 \%$ confluence at $24 \mathrm{~h}$. To permeabilize, cells were rinsed for 2 min in ice-cold PBS, and 612 permeabilized on ice for $10 \mathrm{~min}$ in 25-35 ug/mL digitonin (Calbiochem) in transport buffer (TRB, 20 mM HEPES,

$613110 \mathrm{mM} \mathrm{KOAc}, 2 \mathrm{mM} \mathrm{Mg}(\mathrm{OAc})_{2}, 5 \mathrm{mM}$ NaOAc, $0.5 \mathrm{mM}$ EGTA, $250 \mathrm{mM}$ sucrose, pH 7.4, with freshly added

614 Halt protease inhibitor (1:100, Promega)). The optimal digitonin concentration varied by cell density and

615 passage number and was optimized prior to each assay such that the majority of plasma membranes were

616 permeabilized while maintaining nuclear exclusion of a $70 \mathrm{kD}$ fluorescent dextran (ThermoFisher). The

617 permeabilized cells were washed twice in ice-cold TRB prior to initiating the export assay.

Assay components, including 1,6-hexanediol (Sigma-Aldrich), ATP (pH 7.5, Sigma-Aldrich), RNase A

(ThermoFisher), or RNA oligomers (Table 2, synthesized by IDT or Sigma-Aldrich) were premixed in TRB in 96well plates and equilibrated at the appropriate temperature $\left(4^{\circ} \mathrm{C}, 25^{\circ} \mathrm{C}\right.$, or $\left.37^{\circ} \mathrm{C}\right)$ prior to cell permeabilization.

With the exception of RNase A-containing assays, TRB was routinely supplemented with RNasin Ribonuclease Inhibitor (1000 U/mL, Promega). Following permeabilization, the assay mix was transferred onto permeabilized cells via multichannel pipette and export was allowed to proceed at the temperature $\left(4^{\circ} \mathrm{C}, 25^{\circ} \mathrm{C}\right.$, or $\left.37^{\circ} \mathrm{C}\right)$ and for the time (30-60 min) indicated in the figure legends, prior to fixation in 4\% paraformaldehyde/PBS (Electron Microscopy Sciences) for $15 \mathrm{~min}$. For each replicate, an additional plate of cells was fixed immediately postpermeabilization, designated 'time 0', for the purpose of data normalization across independent biological replicates.

631 Synthesis and nuclear import of the recombinant Rango sensor was carried out as recently described (Hayes 632 et al, 2020, 2021). Briefly, following HeLa cell permeabilization as above, Rango nuclear import assays were 
633 carried out with or without $2.5 \mathrm{mM} \mathrm{ATP} \mathrm{(pH} \mathrm{7.5,} \mathrm{Sigma-Aldrich)} \mathrm{and} \mathrm{HEK} \mathrm{whole} \mathrm{cell} \mathrm{lysate} \mathrm{(2.5} \mathrm{mg/mL} \mathrm{in} \mathrm{TRB),}$

634 at $37^{\circ} \mathrm{C}$ for 30 minutes. A subset of assays included recombinant human importin $\beta$ (71-876), a RanGTP-

635 resistant variant (Drutovic et al, 2020). Cells were fixed for $15 \mathrm{~min}$ in $4 \%$ paraformaldehyde/PBS, washed 2x

636 with PBS containing Hoechst (1:5000), and transferred to 50\% glycerol/PBS for immediate imaging.

\section{Live-cell TDP-43 shuttling assays}

639 HeLa and DLD1 cells were plated in uncoated, optical glass-bottom 96-well plates (CellVis) to achieve $640 \sim 75 \%$ confluence at the time of shuttling assays. For transcriptional inhibition, TDP-43 shuttling was 641 initiated by treatment with actinomycin D (Sigma-Aldrich, in DMSO) or NVP-2 (Tocris Bioscience, in 642 DMSO) at doses/times indicated in the figure legends. For splicing inhibition, cells were pretreated for $4 \mathrm{~h}$ 643 with escalating doses of isoginkgetin (IGK, Millipore-Sigma, in DMSO) or pladienolide B (PLB, Cayman 644 Chemicals, in DMSO), prior to addition of 250 nM NVP-2. For NXF1 ablation experiments, DLD1-wildtype 645 and DLD1-NXF1-AID cells were pretreated for 0-8 hrs with $0.5 \mathrm{mM}$ synthetic auxin (3-indoleacetic acid, 646 Sigma, in ethanol), prior to addition of 250 nM NVP-2. At the conclusion of experiments, cells were fixed in 647 4\% paraformaldehyde/PBS (Electron Microscopy Sciences) for 15 minutes prior to immunostaining.

\section{Immunofluorescence}

650 Paraformaldehyde-fixed cells were rinsed with PBS and simultaneously permeabilized and blocked with $0.1 \%$ 651 Triton-X 100 and 10\% normal goat serum (NGS, Vector Labs) in PBS for 30 min at room temperature. Primary 652 antibody in 10\% NGS/PBS was added to the cells and incubated for 60-90 min at room temperature or 653 overnight at $4^{\circ} \mathrm{C}$. Cells were rinsed $2 x$ with PBS and AF488 or AF647-labeled secondary antibody 654 (ThermoFisher) was added in 10\% NGS/PBS and incubated for $1 \mathrm{~h}$ at room temperature. Cells were rinsed with 655 PBS containing Hoechst 33342 and transferred to $50 \%$ glycerol/PBS for imaging.

\section{RNA labeling}

658 For poly(A)-fluorescence in situ hybridization (FISH), cells were fixed in 10\% formaldehyde (Sigma-Aldrich) in 659 PBS for 20 min, permeabilized in $0.1 \%$ PBS-Tween for 10 min, and washed 3 times in $1 x$ PBS and 2 times in 2x 660 SSC buffer (Sigma-Aldrich) for five min each. Cells were prehybridized for $1 \mathrm{~h}$ in hybridization buffer at $42^{\circ} \mathrm{C}$ 
661 (Thermo), and then incubated in Cy3-oligo-dT(45) probe (IDT, $100 \mathrm{nM}$ in hybridization buffer) overnight at $42^{\circ} \mathrm{C}$.

662 Cells were washed with decreasing concentrations of SSC buffer at $42^{\circ} \mathrm{C}(2 \mathrm{x}$, then $0.5 \mathrm{x}$, then $0.1 \mathrm{x}$ in PBS, for

66320 min each), with Hoechst 33342 nuclear counterstain included in the final wash.

665 For click-chemistry labeling of nascent RNA synthesis, cells were treated with $200 \mu \mathrm{M}$ 5-ethynyl-uridine in 666 culture media for 30 min, fixed with 4\% paraformaldehyde/PBS for 15 min, permeabilized and blocked in $2 \%$ 667 BSA/0.1\%Tx-100 in PBS for 30 min, and labeled with $0.5 \mu \mathrm{M}$ AF488-Picolyl Azide using the Click-\&-Go Cell 668 Reaction Buffer kit according to the manufacturers' instructions (all reagents from Click Chemistry Tools). Cells 669 were subsequently immunolabeled for TDP-43 as described above.

671 High content imaging and data analysis

672 Automated imaging and analysis were carried out using an ImageXpress Micro Confocal high content 673 microscope with MetaXpress software (Molecular Devices) as previously described (Hayes et al, 2020, 2021). 674 Briefly, nine non-overlapping fields per well were imaged at 20x (immortalized cells) or 40x (neurons) 675 magnification in spinning disc confocal mode with $60 \mu \mathrm{m}$ pinhole, with exposures targeting half-maximal 676 saturation (33,000 / 65,536 relative fluorescent units (RFU) in unbinned, 16-bit images). The background677 corrected mean and integrated nuclear and cytoplasmic intensities and the nuclear/cytoplasmic (N/C) ratio were 678 calculated using the translocation-enhanced module. Number and morphometry of nuclear puncta were 679 calculated using the granularity module. The Hoechst counterstain was used to identify the nuclear/cytoplasmic 680 boundary and nuclear and cytoplasmic compartments were set several pixels in and outside of the nuclear 681 boundary to avoid edge effects. All image analysis was carried out on raw, unaltered images. Raw data were 682 uniformly filtered to exclude errors of cell identification (probe intensity $=0$ ) and non-physiologic N/C ratios (N/C $683<0.1$ or $>100$ ). For transient transfections, data were filtered by mean intensity to exclude untransfected cells 684 (<1000 RFU) and highly expressing cells (>45,000 RFU). Resulting data were normalized across technical and 685 biological replicates as percent untreated controls or percent time 0 , as indicated in the figure legends. The 686 mean number of cells/well across replicates is also provided. The number of biological replicates (independent cell passages/experiments) was used as the $\mathrm{N}$ for statistical analyses. 
690 Cells were rinsed in PBS and lysed in TRIzol (ThermoFisher). Total RNA was isolated following the 691 manufacturer's protocol and resuspended in nuclease-free water. First-strand cDNA synthesis was 692 performed with 1ug of total RNA using the High-Capacity cDNA Reverse Transcription Kit (ThermoFisher). 693 qPCR was performed using PowerSYBR Green PCR Master Mix (ThermoFisher) with 10ng of cDNA per 694 well and exon-intron primers (500nM) as listed below, using a QuantStudio 3 Real-Time PCR System.

\section{Nuclear/cytoplasmic fractionation and immunoblotting}

24-48 h post-transfection with V5-tagged TDP-43 and RRM mutants, TDP-43 CRISPR KO HeLa cells were lysed for N/C fractionation and SDS-PAGE with the NE-PER kit (ThermoFisher) according to the manufacturer's instructions. Total protein concentration was measured using the DC Protein Assay kit (BioRad). Nuclear (5 $\mu \mathrm{g}$ total protein) and cytoplasmic (10 $\mu \mathrm{g}$ total protein) fractions were boiled in Laemmli

701 buffer (Bio-Rad), run on Criterion 4-20\% Gels (Bio-Rad), and transferred to nitrocellulose membranes using 702 a TransBlot Turbo system (BioRad). Membranes were blocked with 5\% non-fat milk in TBS-Tween and 703 probed by sequential incubation in primary antibody overnight at $4^{\circ} \mathrm{C}$. Detection was via HRP-conjugated secondary antibodies/chemiluminescence using an ImageQuant LAS 4000 system (GE). Band intensities

\section{ATP quantification}

708 Permeabilized and live cells in TRB were lysed and ATP levels quantified using the CellTiter-Glo luminescence assay (Promega) according to the manufacturers' instructions. Luminescence was measured using a

\section{Image processing for figures}

713 Immunofluorescence images were cropped and minimally processed for figures using Adobe Photoshop $7142021(v 22.4 .3)$ as follows and as indicated in the figure legends. For the purpose of raw intensity comparisons, 715 including the nascent RNA signal (Fig 1 and Suppl fig 1) and the TDP-43 nuclear signal in permeabilized cells 
717 pixels, and those parameters were subsequently applied to all other images. For comparisons of shifts in the

$718 \mathrm{~N} / \mathrm{C}$ ratio (all other figures), the intensity histogram was independently maximized according to the brightest and

719 dimmest pixels in each image, to enable adequate visualization of both the nuclear and cytoplasmic

720 compartments. To aid in data visualization, in selected images the fire pseudo-color LUT was applied using

$721 \mathrm{FIJI} / \mathrm{ImageJ}(\mathrm{v} 2.1 .0 / 1.53 \mathrm{c})$ and the quantitative/linear map is provided in the image. All adjustments were linear

722 (no gamma changes) and applied equally to the entire image. Immunoblots were cropped for space and no

723 other processing was applied. Uncropped immunoblot images are provided in the source data.

Statistical analysis

726 Graphing and statistical analyses were carried out using Prism v9.2.0 (Graphpad), according to the 727 methods detailed in the figure legends.

FIGURE LEGENDS

Figure 1. NVP-2-induced RNA Pol II inhibition promotes TDP-43 nuclear export

A. Newly-synthesized RNAs labeled with AF488-picolyl azide via 5-EU incorporation/'click chemistry' (top) and TDP-43 immunofluorescence (bottom) in HeLa cells treated with DMSO (vehicle) vs. NVP-2 for $1 \mathrm{~h}$. Arrows indicate rRNA puncta unaffected by NVP-2. Scale bar $=25 \mu \mathrm{m}$.

B, C. High content analysis of nascent RNA (AF488-azide) mean nuclear intensity (B) and TDP-43 nuclear 7383 independent biological replicates. Mean \pm SD is shown. The $\mathrm{IC}_{50}$ for $1 \mathrm{~h}$ treatment is indicated, as 739 calculated by non-linear regression.

740 D. RBP N/C ratios in HeLa cells treated with $250 \mathrm{nM}$ NVP-2 for 30 min to $6 \mathrm{~h}$. Selected proteins are labeled 741 (the full panel is detailed in Suppl fig 2). $\mathrm{N}=$ mean of 2716 cells/well. Curves were fit by non-linear regression using the mean of 2-4 biological replicates per RBP. 
Supplemental figure 1. Transcriptional blockade-induced TDP-43 nuclear export in HeLa and neurons

A. Nascent RNAs labeled with AF488-picolyl azide via 5-EU incorporation/'click chemistry' (top) and TDP43 immunofluorescence (bottom) in HeLa cells treated with DMSO (vehicle) vs. Actinomycin D for $1 \mathrm{~h}$.

748 Scale bar $=25 \mu \mathrm{m}$.

749 B, C. High content analysis of nascent RNA (AF488-azide) mean nuclear intensity (B) and TDP-43 nuclear 750 to cytoplasmic $(\mathrm{N} / \mathrm{C})$ ratio $(\mathrm{C})$ expressed as percent DMSO control. $\mathrm{N}=$ mean of 2540 cells/well. Mean $\pm \mathrm{SD}$ 751 of 3-4 biological replicates per condition is shown. The $\mathrm{IC}_{50}$ for $1 \mathrm{~h}$ treatment is indicated, as calculated by 752 non-linear regression.

753 D, E. Mean nuclear vs. cytoplasmic intensity of TDP-43 following NVP-2 (D) or Actinomycin D (E) 754 treatment. These are the source data that were used to calculate the N/C ratios in Fig 1B,C and SuppI 755 figure $1 \mathrm{~B}, \mathrm{C}$. The $\mathrm{IC}_{50}$ for $1 \mathrm{~h}$ treatment is indicated, as calculated by non-linear regression.

756 F. Nascent RNAs labeled with AF488-picolyl azide via 5-EU incorporation/'click chemistry' (top) and TDP75743 immunofluorescence (bottom) in mouse primary cortical neurons cells treated with DMSO (vehicle), 250 $758 \mathrm{nM}$ NVP-2, or $1 \mu \mathrm{M}$ Actinomycin $\mathrm{D}$ for $3 \mathrm{~h}$. Arrows indicate rRNA puncta unaffected by NVP-2. Scale bar $=$ $75925 \mu \mathrm{m}$.

760 G-J. High content analysis of nascent RNA (AF488-azide) mean nuclear intensity and TDP-43 nuclear to 761 cytoplasmic $(\mathrm{N} / \mathrm{C})$ ratio in primary neurons treated with NVP-2 $(\mathrm{G}, \mathrm{H})$ or Actinomycin $D(\mathrm{I}, \mathrm{J})$, expressed as 762 percent DMSO control. $\mathrm{N}=$ mean of $534 \mathrm{cells} /$ well in each of of 2 biological replicates. Mean $\pm \mathrm{SD}$ is shown. 763 K. Raw N/C ratio of endogenous TDP-43 vs. TDP-43-YFP and TDP-43-V5 in transiently transfected HeLa 764 cells following $1-4 \mathrm{~h}$ treatment with $250 \mathrm{nM} \mathrm{NVP-2}$. N= mean of 2070 cells/well in each of of 3 biological 765 replicates. Mean \pm SD is shown.

\section{Supplemental figure 2. Comparison of NVP-2-induced shuttling among RBPs}

768 A. RBP N/C ratios in HeLa cells after 30 min (left) or $6 \mathrm{~h}$ (right) of $250 \mathrm{nM} \mathrm{NVP-2}$ treatment, expressed as $769 \%$ time $0 . \mathrm{N}=$ mean of 2716 cells/well. Mean of $2-4$ biological replicates per protein is shown. 
773 Figure 2. TDP-43 exits the nucleus by passive diffusion in permeabilized cells

774 A. Schematic of permeabilized cell TDP-43 passive nuclear export assay. IF = immunofluorescence.

775 B. TDP-43 immunofluorescence (top) and Hoechst nuclear stain (bottom) in permeabilized HeLa cells fixed

776 immediately post-permeabilization $(0 \mathrm{~min})$ and $60 \mathrm{~min}$ post-permeabilization, following incubation at $4^{\circ} \mathrm{C}$ or

$77737^{\circ} \mathrm{C}$. The intensity histogram for all TDP-43 images was normalized relative to the 0 min control, prior to 778 application of the pseudo-color LUT (middle) to illustrate relative TDP-43 nuclear intensity. Scale bar $=50$

$779 \mu \mathrm{m}$.

780 C. Integrated nuclear intensity of TDP-43 in permeabilized HeLa cells over time at $4^{\circ} \mathrm{C}$ vs. $37^{\circ} \mathrm{C}$ expressed

781 as percent of time $0 . \mathrm{N}=$ mean of 2185 cells/well/condition in each of 4 independent biological replicates.

782 D. TDP-43 immunofluorescence staining (top) and Hoechst nuclear stain (bottom) in permeabilized HeLa

783 cells incubated for 30 minutes post-permeabilization at $4^{\circ} \mathrm{C}$ vs. $37^{\circ} \mathrm{C}$ with increasing concentrations of 1,6 784 hexanediol. The intensity histogram for all TDP-43 images was normalized relative to $0 \% \mathrm{HD}\left(4^{\circ} \mathrm{C}\right)$. Scale $785 \quad$ bar $=50 \mu \mathrm{m}$.

786 E. Integrated nuclear intensity of TDP-43 in permeabilized HeLa cells incubated for 30 minutes at $4^{\circ} \mathrm{C}$ vs. $78737^{\circ} \mathrm{C}$ with increasing concentrations of 1,6 -hexanediol. Data are expressed as percent untreated, $4^{\circ} \mathrm{C} . \mathrm{N}=$ 788 mean of 2389 cells/well/condition in each of 3 independent biological replicates.

789 In $C, E,{ }^{* *} p<0.01,{ }^{* *} p<0.001,{ }^{* \star * *} p<0.0001$ by 2 -way ANOVA with Tukey's multiple comparisons test.

791 Supplemental figure 3. Validation of permeabilized cell passive export assay.

792 A. Evaluation of nuclear pore and nuclear membrane integrity by exclusion of 70 kD Texas Red-dextran in 793 digitonin-permeabilized HeLa cells in transport buffer. Scale bar $=20 \mu \mathrm{m}$.

794 B. ATP luciferase assay in intact versus digitonin-permeabilized HeLa cells, measured immediately 795 following digitonin permeabilization. $\mathrm{N}=3$ independent biological replicates. ${ }^{* \star * *} \mathrm{p}<0.0001$ by unpaired 796 Student's t-test.

797 C. TDP-43 integrated nuclear intensity in permeabilized HeLa cells incubated for 30 min at $37^{\circ} \mathrm{C}$ with or 798 without $100 \mathrm{nM}$ Leptomycin B (LMB) treatment during permeabilization, wash, and export phases. Data are expressed as percent time $0 . \mathrm{N}=$ mean of 3005 cells/well in each of 6 technical replicates. 
D. TDP-43 integrated nuclear intensity in permeabilized HeLa cells incubated for 30 min at $37^{\circ} \mathrm{C}$ with

801 increasing concentrations of ATP (0 to $2 \mathrm{mM})$. Data are expressed as percent time $0 . \mathrm{N}=$ mean of 2883

802 cells/well/condition in each of 3 independent biological replicates. NS = not significant, one-way ANOVA 803 with Tukey's post-hoc test.

804 E. Rango integrated nuclear intensity in permeabilized HeLa cells incubated for 30 min at $37^{\circ} \mathrm{C}$ with or 805 without HEK cell lysate, ATP (2.5 mM), and dominant-negative importin- $\beta$ (71-876) mutant. Data are 806 expressed as percent untreated (dotted line). $\mathrm{N}=$ mean of 1289 cells/well in each of 2 technical replicates.

Figure 3. Acute NXF1 ablation does not alter NVP-2-induced TDP-43 nuclear export

A. NXF1 immunoblot in DLD1-wild-type vs. DLD1-NXF1-AID cells treated with $0.5 \mathrm{mM}$ auxin for 0-4 h. Note the increased molecular weight for AID-tagged NXF1 (*) vs endogenous NXF1 (>).

B. Poly(A)-FISH (Cy3-OligodT(45)) in DLD1-wild-type vs. DLD1-NXF1-AID cells treated with 0.5 mM auxin

812 for designated time. Scale bar $=25 \mu \mathrm{m}$.

813 C. Poly(A)-RNA N/C ratio in DLD1-wild-type vs. DLD1-NXF1-AID cells treated with $0.5 \mathrm{mM}$ auxin for 0-8 h.

814 Data are expressed as percent wild-type untreated cells. $\mathrm{N}=$ mean of 3476 cells/well in each of 4

815 independent biological replicates. Mean \pm SD is shown. ${ }^{*} p<0.05,{ }^{* \star * *} p<0.0001$ versus wild-type, by 2 -way

816 ANOVA with Sidak's multiple comparisons test.

817 D. TDP-43 N/C ratio in DLD1-wild-type cells (left) and DLD1-NXF1-AID cells (right) pretreated with $0.5 \mathrm{mM}$ 818 auxin for 0-8 h, followed by $2 \mathrm{~h}$ auxin only (-NVP-2) or auxin + 250 nM NVP-2 (+NVP-2). Data in both

819 panels are normalized to untreated DLD1-wild-type cells (dotted line).

820 E. TDP-43 N/C ratio in NVP-2 treated vs. untreated cells (+NVP-2 / -NVP-2) in DLD1-wild-type (black) vs.

821 DLD1-NXF1-AID (red) cells. These are the same data as in (D), adjusted for differences in the steady-state 822 TDP-43 N/C ratio, to permit comparison of NVP-2-induced TDP-43 nuclear exit.

823 In D-E, $\mathrm{N}=$ mean of 4610 cells/well in each of 4 independent biological replicates. Mean \pm SD is shown. $824{ }^{* * *} \mathrm{P}<0.0001$ for indicated comparisons by 2-way ANOVA with Sidak's multiple comparisons test. 
827 A. Schematic depicting addition of RNase (A-C) or RNA oligomers (D-G) to permeabilized cell TDP-43 828 passive export assay.

829 B. Endogenous TDP-43 immunofluorescence (top) and Hoechst (bottom) in permeabilized HeLa cells 830 incubated for 30 min at $4^{\circ} \mathrm{C}$ with or without RNase A. Arrows highlight formation of nuclear puncta by 831 residual nuclear TDP-43. Scale bar $=25 \mu \mathrm{m}$.

832 C. TDP-43 integrated nuclear intensity in permeabilized HeLa cells incubated for 30 min at $4^{\circ} \mathrm{C}$ vs. $37^{\circ} \mathrm{C}$ 833 with increasing concentrations of RNase A. Data are expressed as percent untreated cells at $4^{\circ} \mathrm{C} . \mathrm{N}=$ 834 mean of 2552 cells/well/condition in each of 4 independent biological replicates. ${ }^{* * *} p<0.0001$ versus time 0 835 by 2-way ANOVA with Tukey's multiple comparisons test. D. TDP-43 integrated nuclear intensity in permeabilized HeLa cells incubated for 30 min at $4^{\circ} \mathrm{C}$ with 837 increasing concentrations of A16, (GU)8, or 'AUG12' oligomers. Data are expressed as percent untreated 838 cells. $\mathrm{N}=$ mean of 2968 cells/well/condition in each of 4 independent biological replicates.

839 E. TDP-43 integrated nuclear intensity in permeabilized HeLa cells incubated at $4{ }^{\circ} \mathrm{C}, 25^{\circ} \mathrm{C}$ or $37^{\circ} \mathrm{C}$ for 30 840 min with increasing concentrations of $(\mathrm{GU}) 8$. Data are expressed as percent untreated cells. $\mathrm{N}=\mathrm{mean}$ of 8411039 cells/well/condition in each of 2 technical replicates.

842 F. Integrated nuclear intensity of designated nuclear RBPs in permeabilized HeLa cells incubated for 30 843 minutes at $4^{\circ} \mathrm{C}$ with increasing concentrations (GU)8. Data are expressed as percent untreated cells. Note: 844 TDP-43 data are the same as in (D). $\mathrm{N}=$ mean of 3421 cells/well in each of 4 independent biological 845 replicates.

846 G. Integrated nuclear intensity of designated nuclear RBPs in permeabilized HeLa cells incubated for 30 847 minutes at $4^{\circ} \mathrm{C}$ with increasing concentrations of the indicated RNA oligomers. Data are expressed as 848 percent untreated cells. $\mathrm{N}=$ mean of 3293 cells/well/condition in each of 3-4 independent biological 849 replicates.

850 H. Schematic of live HeLa cell transfection with protected RNA oligomers.

851 I. TDP-43 N/C ratio $5 \mathrm{~h}$ after transfection with protected A13 or (GU)6 RNA oligomers. Data are expressed 852 as percent untreated cells. $\mathrm{N}=$ mean of 2887 cells/well/condition in each of 3 independent biological 853 replicates. 
J. RBP N/C ratios $5 \mathrm{~h}$ after transfection with protected (GU)6 RNA oligomers. Data are expressed as

855 percent untreated cells. Note: TDP-43 data are the same as those shown for (GU)6 in (I). N = mean of

8562555 cells/well/condition in each of 3 independent biological replicates.

857 In F,G,J: The RBP labeled in red corresponds to the most closely-predicted binding partner for that motif, 858 and green indicates an RBP with a moderately-similar motif. Gray and black labels correspond to RBPs 859 with no or low predicted binding activity to the given sequence.

860 In D-J: RNA oligomer sequences are detailed in Table 2. Mean \pm SD is shown. IC50 values were 861 calculated by non-linear regression.

862

\section{Supplemental figure 4. Nuclear and RNA integrity controls.}

864 A. Integrated nuclear intensity of DDX19b and Nup50 versus TDP-43 in permeabilized HeLa cells 865 incubated for 30 minutes at $4^{\circ} \mathrm{C}$ (left) or $37^{\circ} \mathrm{C}$ (right) with increasing concentrations of RNase A. Data are 867 SD is shown.

868 B. Integrated nuclear intensity of TDP-43 in permeabilized HeLa cells incubated for 30 or 60 min at $37^{\circ} \mathrm{C}$ 869 with or without RNasin ribonuclease inhibitor. Data are expressed as percent time 0 , untreated cells. $\mathrm{N}=$ 870 mean of 3262 cells/well in each of 2 independent replicates.

872 Figure 5. Inhibition of pre-mRNA splicing promotes TDP-43 nuclear accumulation

873 A. TDP-43 immunofluorescence in HeLa cells treated with IGK for $4 \mathrm{~h}$, followed by $2 \mathrm{~h}$ of IGK only or IGK + $874250 \mathrm{mM}$ NVP-2. Scale bar $=25 \mu \mathrm{m}$.

875 B. TDP-43 N/C in IGK or IGK + NVP-2-treated cells, expressed as \% untreated.

876 C. TDP-43 N/C ratio (same data as part B) expressed as \% IGK only, to permit comparison of NVP-2-

877 induced nuclear exit. $\mathrm{IC}_{50}$ calculated by non-linear regression.

878 D. TDP-43 immunofluorescence in HeLa cells treated with PLB for $4 \mathrm{~h}$, followed by $2 \mathrm{~h}$ of PLB only or PLB $879+250 \mathrm{mM}$ NVP-2. Scale bar $=25 \mu \mathrm{m}$.

880 E. TDP-43 N/C in PLB or PLB + NVP-2-treated cells, expressed as \% untreated. 
881 F. TDP-43 N/C ratio (same data as part E) expressed as \% PLB only, to permit comparison of NVP-2-

882 induced nuclear exit. $\mathrm{IC}_{50}$ calculated by non-linear regression.

883 In A,C: The intensity histogram for each image was independently maximized across the full range to

884 enable comparison of nuclear vs. cytoplasmic signal, and a pseudo-color LUT was then applied (see linear 885 scale at right).

886 In B,C: $\mathrm{N}=$ mean of 2357 cells/well in each of 4 independent biological replicates. Mean \pm SD is shown.

887 In E,F: $\mathrm{N}=$ mean of 2720 cells/well in each of 4 independent biological replicates. Mean \pm SD is shown.

888 In $B, C, E, F:{ }^{* * *} p<0.001,{ }^{* * * *} p<0.0001$ by 2 -way ANOVA with Tukey's multiple comparisons test.

889 Comparisons as indicated with untreated cells (brackets) or between NVP-2-treated and untreated cells at 890 each dose of splicing inhibitor (no brackets).

891 See suppl fig 5 for validation of IGK and PLB-induced intron accumulation by qRT-PCR.

892

Supplemental figure 5. Validation of IGK and PLB-induced intron accumulation

A-C. qRT-PCR quantification of $\beta$-tubulin $(A)$, actin (B), and DNAJB1 (C) pre-mRNAs using exon-intron 895 primer pairs, normalized to U6 snRNA expression. HeLa cells were treated for $4 \mathrm{~h}$ with IGK or PLB at 896 indicated doses. Mean $\pm \mathrm{SD}$ is shown for $\mathrm{N}=2$ technical replicates.

Figure 6. Mutation or deletion of TDP-43 RRM domains disrupts TDP-43 nuclear localization

899 A. Schematic of V5-tagged TDP-43 RRM mutant constructs (top) and V5 immunofluorescence (bottom) in 900 transiently transfected TDP-43 CRISPR KO HeLa cells, after $1 \mathrm{~h}$ treatment with DMSO vs. 250 nM NVP-2.

901 The intensity histogram for each image was independently maximized across the full range to enable 902 comparison of nuclear vs. cytoplasmic signal, and a pseudo-color LUT was then applied (see linear scale 903 at right). See suppl fig 6 for validation of CRISPR knockdown of endogenous TDP-43. Scale bar $=25 \mu \mathrm{m}$. 904 B. Raw N/C ratio of TDP-43 wild-type vs. RRM mutant constructs in transiently transfected TDP-43

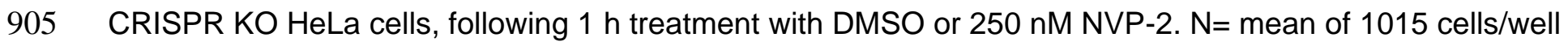
906 in each of 4 replicates (2 technical and 2 biological). Mean \pm SD is shown. 
907 C. N/C fractionation and immunoblotting of TDP-43 CRISPR KO HeLa cells, transiently transfected with

908 V5-tagged TDP-43 constructs and treated for $3 \mathrm{~h}$ with DMSO vs. 250 nM NVP-2. Lamin B1 = nuclear

909 marker. GAPDH = cytoplasmic marker.

910 D. N/C ratio of V5 nuclear vs. cytoplasmic signal calculated from $\mathrm{N}=3$ immunoblots (derived from 2

911 biological replicates). Ratios are expressed as \% WT DMSO-treated cells.

912 In B,D: ns = not significant, ${ }^{* * *} \mathrm{p}<0.0001$ by 2-way ANOVA with Tukey's multiple comparisons test.

\section{Supplemental figure 6. TDP-43 CRISPR KO cell validation and effect of HSP70i on TDP-43}

915 granularity and nuclear localization.

916 A. TDP-43 gene expression in wild-type vs. CRISPR KO HeLa cell lines by qRT-PCR, normalized to

917 GAPDH expression. N=3 technical replicates.

918 B. Immunoblot comparing endogenous TDP-43 protein expression in wild-type vs. CRISPR KO HeLa cells

919 (left). Level of expression of transiently transfected V5-tagged constructs vs. endogenous TDP-43, and 920 immunodetection by TDP-43 (left) and V5 (right) antibodies is also shown.

921 C. YFP epifluorescence in TDP-43 CRISPR KO cells transiently transfected with TDP-43-5FL-YFP, before 922 and after $3 \mathrm{~h}$ treatment with HSP70i $(50 \mu \mathrm{M})$. Arrows highlight examples of reduction in number of nuclear 923 granules. Note that moderate cell migration occurs over the timecourse of the assay. Scale bar $=50 \mu \mathrm{m}$. 924 D. High content analysis of number of TDP-43-YFP and TDP-43-5FL-YFP granules per nucleus in DMSO 925 vs. HSP70i-treated cells, assessed via live, time-lapse imaging. $\mathrm{N}=$ mean of 2171 cells/well/condition in 926 each of two independent biological replicates. Mean \pm SD is shown.

927 E. V5 immunofluorescence in TDP-43 CRISPR KO cells transiently transfected with V5-tagged wild-type 928 and RRM mutant TDP-43 constructs, and treated for $3 \mathrm{~h}$ with DMSO vs. HSP70i (50 $\mu$ M). Note: Rare 929 examples of puncta-containing nuclei are shown (arrows) which constitute only a minority of the cell 930 population as quantified in $(F)$. The intensity histogram for each image was independently maximized 931 across the full range. Given the intense fluorescence of the puncta, this prevents visualization of the N/C 932 gradients which are better appreciated in the more representative images in Fig 6A. Scale bar $=25 \mu \mathrm{M}$. 933 F-H. High content granularity analysis in TDP-43 CRISPR KO cells transiently transfected with V5- or YFP934 tagged wild-type and RRM mutant TDP-43 constructs, and treated with DMSO or HSP70i (50 $\mu$ M) for $3 \mathrm{~h}$. 
935 Parameters include \% cells with $\geq 1$ puncta $(F)$, \# puncta/nucleus (G, expressed as \% DMSO), and mean

936 puncta area $(\mathrm{H}$, expressed as \% DMSO). $\mathrm{N}=$ mean of 1156 cells/well/condition in each of three

937 independent biological replicates. Mean \pm SD is shown.

938 I. N/C ratio of V5 immunofluorescence signal, in TDP-43 CRISPR KO cells transiently transfected with V5-

939 tagged wild-type and RRM mutant TDP-43 constructs, and treated with DMSO, NVP2 (250 nM), HSP70i

$940(50 \mu \mathrm{M})$, or both for 3h. Data are expressed as percent wild-type DMSO-treated cells. $\mathrm{N}=$ mean of 788

941 cells/well/condition in each of three independent biological replicates.

942 In F-I: ns = not significant, ${ }^{*} \mathrm{p}<0.05,{ }^{* *} \mathrm{p}<0.01,{ }^{* * *} \mathrm{p}<0.001,{ }^{* * * *} \mathrm{p}<0.0001$ for designated comparisons by $2-$

943 way ANOVA with Sidak's multiple comparisons test.

Figure 7. Mechanisms coupling TDP-43 nuclear localization with nuclear GU-rich pre-mRNA binding and abundance. Arrow size corresponds to predicted balance under normal physiologic conditions. See text for discussion.

950 Lin Xue, Svetlana Vidensky, and Lin Jin provided expert technical assistance. Pei-Hsun Wu provided 951 imaging assistance. Lyudmila Mamedova and Barbara Smith provided administrative support. This 952 research was supported by NIH K08NS104273 and R01NS123538 (L.R.H.), DOD/CDRMP 953 W81XWH1910209 (J.D.R. and L.R.H.), and the Robert Packard Center for ALS Research (L.R.H. and 954 P.K.).

\section{AUTHOR CONTRIBUTIONS}

957 L.D. - conceptualization, methodology, investigation, validation, formal analysis, visualization, writing958 original draft, writing-review \& editing; B.Z. - methodology, investigation, writing-review \& editing; V.A. 959 methodology, resources, writing-review \& editing; M.D. - resources, supervision, writing-review \& editing; 960 J.D.R. - supervision, funding acquisition, writing-review \& editing; P.K. - conceptualization, methodology, 961 investigation, resources, visualization, writing-original draft, writing-review \& editing, funding acquisition; 
L.R.H. - conceptualization, methodology, investigation, validation, formal analysis, visualization, writing-

963

964

original draft, writing-review \& editing, supervision, funding acquisition.

\section{CONFLICTS OF INTEREST}

The authors declare that they have no conflicts of interest to report.

\section{REFERENCES}

Adam SA, Marr RS \& Gerace L (1990) Nuclear protein import in permeabilized mammalian cells requires soluble cytoplasmic factors. J Cell Biol 111: 807-816

Afroz T, Hock E-M, Ernst P, Foglieni C, Jambeau M, Gilhespy LAB, Laferrière F, Maniecka Z, Plückthun A, Mittl P, et al (2017) Functional and dynamic polymerization of the ALS-linked protein TDP-43 antagonizes its pathologic aggregation. Nature Communications 8: 45

Aksenova V, Smith A, Lee H, Bhat P, Esnault C, Chen S, Iben J, Kaufhold R, Yau KC, Echeverria C, et al (2020) Nucleoporin TPR is an integral component of the TREX-2 mRNA export pathway. Nature Communications 11: 4577

Arai T, Hasegawa M, Akiyama H, Ikeda K, Nonaka T, Mori H, Mann D, Tsuchiya K, Yoshida M, Hashizume $\mathrm{Y}$, et al (2006) TDP-43 is a component of ubiquitin-positive tau-negative inclusions in frontotemporal lobar degeneration and amyotrophic lateral sclerosis. Biochem Bioph Res Co 351: 602-611

Archbold HC, Jackson KL, Arora A, Weskamp K, Tank EMH, Li X, Miguez R, Dayton RD, Tamir S, Klein $\mathrm{RL}$, et al (2018) TDP43 nuclear export and neurodegeneration in models of amyotrophic lateral sclerosis and frontotemporal dementia. Scientific reports 8: 4606

Avendaño-Vázquez SE, Dhir A, Bembich S, Buratti E, Proudfoot N \& Baralle FE (2012) Autoregulation of TDP-43 mRNA levels involves interplay between transcription, splicing, and alternative polyA site selection. Gene Dev 26: 1679-1684

Ayala YM, Zago P, D’Ambrogio A, XU Y-F, Petrucelli L, Buratti E \& Baralle FE (2008) Structural determinants of the cellular localization and shuttling of TDP-43. J Cell Sci 121:3778-3785

Baejen C, Torkler P, Gressel S, Essig K, Söding J \& Cramer P (2014) Transcriptome Maps of mRNP Biogenesis Factors Define Pre-mRNA Recognition. Mol Cell 55: 745-757

Bastiaens P, Caudron M, Niethammer P \& Karsenti E (2006) Gradients in the self-organization of the mitotic spindle. Trends Cell Biol 16: 125-134

Bhardwaj A, Myers MP, Buratti E \& Baralle FE (2013) Characterizing TDP-43 interaction with its RNA targets. Nucleic acids research 41: 5062-5074

Borroni B, Bonvicini C, Alberici A, Buratti E, Agosti C, Archetti S, Papetti A, Stuani C, Luca MD, Gennarelli $\mathrm{M}$, et al (2009) Mutation within TARDBP leads to Frontotemporal Dementia without motor neuron disease. Hum Mutat 30: E974-E983

Boswell SA, Snavely A, Landry HM, Churchman LS, Gray JM \& Springer M (2017) Total RNA-seq to identify pharmacological effects on specific stages of mRNA synthesis. Nat Chem Biol 13: 501-507

Bresson S \& Tollervey D (2018) Surveillance-ready transcription: nuclear RNA decay as a default fate. Open Biol 8: 170270

Broeck LV, Callaerts P \& Dermaut B (2014) TDP-43-mediated neurodegeneration: towards a loss-offunction hypothesis? Trends in Molecular Medicine 20: 66-71

Bruun GH, Doktor TK, Borch-Jensen J, Masuda A, Krainer AR, Ohno K \& Andresen BS (2016) Global identification of hnRNP A1 binding sites for SSO-based splicing modulation. Bmc Biol 14: 54

Buratti E (2015) Chapter One Functional Significance of TDP-43 Mutations in Disease. Adv Genet 91: 1-53

Buratti E \& Baralle FE (2001) Characterization and Functional Implications of the RNA Binding Properties of Nuclear Factor TDP-43, a Novel Splicing Regulator ofCFTR Exon 9*. J Biol Chem 276: 36337-36343

Butti Z \& Patten SA (2019) RNA Dysregulation in Amyotrophic Lateral Sclerosis. Frontiers Genetics 9: 712

Cáceres JF, Screaton GR \& Krainer AR (1998) A specific subset of SR proteins shuttles continuously between the nucleus and the cytoplasm. Genes \& Development 12: 55-66 
1012 Carter GC, Hsiung C-H, Simpson L, Yang H \& Zhang X (2021) N-terminal Domain of TDP43 Enhances

1013

1014

1015

1016

1017

1018

1019

1020

1021

1022

1023

1024

1025

1026

1027

1028

1029

1030

1031

1032

1033

1034

1035

1036

1037

1038

1039

1040

1041

1042

1043

1044

1045

1046

1047

1048

1049

1050

1051

1052

1053

1054

1055

1056

1057

1058

1059

1060

1061

1062

1063

1064

1065
Liquid-Liquid Phase Separation of Globular Proteins. J Mol Biol 433: 166948

Carvalho T, Martins S, Rino J, Marinho S \& Carmo-Fonseca M (2017) Pharmacological inhibition of the spliceosome subunit SF3b triggers exon junction complex-independent nonsense-mediated decay. $J$ Cell Sci 130: 1519-1531

Cassany A \& Gerace L (2009) Reconstitution of nuclear import in permeabilized cells. Methods in molecular biology (Clifton, NJ) 464: 181-205

Chi B, O'Connell JD, locolano AD, Coady JA, Yu Y, Gangopadhyay J, Gygi SP \& Reed R (2018a) The neurodegenerative diseases ALS and SMA are linked at the molecular level via the ASC-1 complex. Nucleic acids research 46: 11939-11951

Chi B, O'Connell JD, Yamazaki T, Gangopadhyay J, Gygi SP \& Reed R (2018b) Interactome analyses revealed that the U1 snRNP machinery overlaps extensively with the RNAP II machinery and contains multiple ALS/SMA-causative proteins. Sci Rep-uk 8: 8755

Choi HS, Hwang CK, Song KY, Law P-Y, Wei L-N \& Loh HH (2009) Poly(C)-binding proteins as transcriptional regulators of gene expression. Biochem Bioph Res Co 380: 431-436

Cohen TJ, Hwang AW, Restrepo CR, Yuan C-X, Trojanowski JQ \& Lee VMY (2015) An acetylation switch controls TDP-43 function and aggregation propensity. Nature Communications 6: 5845

Colbeau A, Nachbaur J \& Vignais PM (1971) Enzymic characterization and lipid composition of rat liver subcellular membranes. Biochimica et biophysica acta 249: 462-492

Conicella AE, Dignon GL, Zerze GH, Schmidt HB, D'Ordine AM, Kim YC, Rohatgi R, Ayala YM, Mittal J \& Fawzi NL (2020) TDP-43 $\alpha$-helical structure tunes liquid-liquid phase separation and function. Proc National Acad Sci 117: 5883-5894

Conicella AE, Zerze GH, Mittal J \& Fawzi NL (2016) ALS Mutations Disrupt Phase Separation Mediated by a-Helical Structure in the TDP-43 Low-Complexity C-Terminal Domain. Structure 24: 1537-1549

Corley M, Burns MC \& Yeo GW (2020) How RNA-Binding Proteins Interact with RNA: Molecules and Mechanisms. Mol Cell 78: 9-29

Day RN \& Davidson MW (2009) The fluorescent protein palette: tools for cellular imaging. Chem Soc Rev 38: 2887-2921

Deerlin VMV, Leverenz JB, Bekris LM, Bird TD, Yuan W, Elman LB, Clay D, Wood EM, Chen-Plotkin AS, Martinez-Lage M, et al (2008) TARDBP mutations in amyotrophic lateral sclerosis with TDP-43 neuropathology: a genetic and histopathological analysis. The Lancet Neurology 7: 409-416

Drutovic D, Duan X, Li R, Kalab P \& Solc P (2020) RanGTP and importin $\beta$ regulate meiosis I spindle assembly and function in mouse oocytes. Embo J 39: e101689

Ederle H \& Dormann D (2017) TDP-43 and FUS en route from the nucleus to the cytoplasm. FEBS Letters 591: 1489-1507

Ederle H, Funk C, Abou-Ajram C, Hutten S, Funk EBE, Kehlenbach RH, Bailer SM \& Dormann D (2018) Nuclear egress of TDP-43 and FUS occurs independently of Exportin-1/CRM1. Scientific reports 8: 7084

Elden AC, Kim H-J, Hart MP, Chen-Plotkin AS, Johnson BS, Fang X, Armakola M, Geser F, Greene R, Lu $\mathrm{MM}$, et al (2010) Ataxin-2 intermediate-length polyglutamine expansions are associated with increased risk for ALS. Nature 466: 1069-1075

Falcón-Pérez JM, Nazarian R, Sabatti C \& Dell'Angelica EC (2005) Distribution and dynamics of Lamp1containing endocytic organelles in fibroblasts deficient in BLOC-3. J Cell Sci 118: 5243-5255

Fan XC \& Steitz JA (1998) HNS, a nuclear-cytoplasmic shuttling sequence in HuR. Proc National Acad Sci 95: 15293-15298

Flores BN, Li X, Malik AM, Martinez J, Beg AA \& Barmada SJ (2019) An Intramolecular Salt Bridge Linking TDP43 RNA Binding, Protein Stability, and TDP43-Dependent Neurodegeneration. Cell Reports 27: 1133-1150.e8

François-Moutal L, Perez-Miller S, Scott DD, Miranda VG, Mollasalehi N \& Khanna M (2019) Structural Insights Into TDP-43 and Effects of Post-translational Modifications. Frontiers in molecular neuroscience 12: 1199

Freibaum BD, Chitta RK, High AA \& Taylor JP (2010) Global analysis of TDP-43 interacting proteins reveals strong association with RNA splicing and translation machinery. Journal of proteome research 9: 1104-1120 
1066

1067

1068

1069

1070

1071

1072

1073

1074

1075

1076

1077

1078

1079

1080

1081

1082

1083

1084

1085

1086

1087

1088

1089

1090

1091

1092

1093

1094

1095

1096

1097

1098

1099

1100

1101

1102

1103

1104

1105

1106

1107

1108

1109

1110

1111

1112

1113

1114

1115

1116

1117

1118

1119

1120

French RL, Grese ZR, Aligireddy H, Dhavale DD, Reeb AN, Kedia N, Kotzbauer PT, Bieschke J \& Ayala YM (2019) Detection of TAR DNA-binding protein 43 (TDP-43) oligomers as initial intermediate species during aggregate formation. Journal of Biological Chemistry 294: 6696-6709

Frey S, Rees R, Schünemann J, Ng SC, Fünfgeld K, Huyton T \& Görlich D (2018) Surface Properties Determining Passage Rates of Proteins through Nuclear Pores. Cell 174: 202-217.e9

Furlanis E, Traunmüller L, Fucile G \& Scheiffele P (2019) Landscape of ribosome-engaged transcript isoforms reveals extensive neuronal-cell-class-specific alternative splicing programs. Nat Neurosci 22: 1709-1717

Gasset-Rosa F, Lu S, Yu H, Chen C, Melamed Z, Guo L, Shorter J, Cruz SD \& Cleveland DW (2019) Cytoplasmic TDP-43 De-mixing Independent of Stress Granules Drives Inhibition of Nuclear Import, Loss of Nuclear TDP-43, and Cell Death. Neuron 102: 339-357.e7

Gasteiger E, Hoogland C, Gattiker A, Duvaud S, Wilkins MR, Appel RD \& Bairoch A (2005) The Proteomics Protocols Handbook. 571-607

Gilbertson S, Federspiel JD, Hartenian E, Cristea IM \& Glaunsinger B (2018) Changes in mRNA abundance drive shuttling of RNA binding proteins, linking cytoplasmic RNA degradation to transcription. eLife 7: e37663

Gitcho MA, Baloh RH, Chakraverty S, Mayo K, Norton JB, Levitch D, Hatanpaa KJ, White CL, Bigio EH, Caselli R, et al (2008) TDP-43 A315T mutation in familial motor neuron disease. Ann Neurol 63: 535538

Gopal PP, Nirschl JJ, Klinman E \& Holzbaur ELF (2017) Amyotrophic lateral sclerosis-linked mutations increase the viscosity of liquid-like TDP-43 RNP granules in neurons. Proc National Acad Sci 114: E2466-E2475

Goss DJ \& Kleiman FE (2013) Poly(A) binding proteins: are they all created equal? Wiley Interdiscip Rev Rna 4: 167-179

Grünwald D, Singer RH \& Rout M (2011) Nuclear export dynamics of RNA-protein complexes. Nature 475: 333-341

Hafner M, Katsantoni M, Köster T, Marks J, Mukherjee J, Staiger D, Ule J \& Zavolan M (2021) CLIP and complementary methods. Nat Rev Methods Primers 1:20

Hayes LR, Duan L, Bowen K, Kalab P \& Rothstein JD (2020) C9orf72 arginine-rich dipeptide repeat proteins disrupt karyopherin-mediated nuclear import. eLife 9: e51685

Hayes LR, Duan L, Vidensky S \& Kalab P (2021) Nuclear Transport Assays in Permeabilized Mouse Cortical Neurons. J Vis Exp, doi: 10.3791/62710

Hermey G, Blüthgen N \& Kuhl D (2017) Neuronal activity-regulated alternative mRNA splicing. Int J Biochem Cell Biology 91: 184-193

Hodge CA, Tran EJ, Noble KN, Alcazar-Roman AR, Ben-Yishay R, Scarcelli JJ, Folkmann AW, Shav-Tal Y, Wente SR \& Cole CN (2011) The Dbp5 cycle at the nuclear pore complex during mRNA export I: dbp5 mutants with defects in RNA binding and ATP hydrolysis define key steps for Nup159 and Gle1. Genes \& Development 25: 1052-1064

Jaffrey SR \& Wilkinson MF (2018) Nonsense-mediated RNA decay in the brain: emerging modulator of neural development and disease. Nat Rev Neurosci 19: 715-728

Jain N, Lin H-C, Morgan CE, Harris ME \& Tolbert BS (2017) Rules of RNA specificity of hnRNP A1 revealed by global and quantitative analysis of its affinity distribution. Proceedings of the National Academy of Sciences 114: 2206-2211

Jao CY \& Salic A (2008) Exploring RNA transcription and turnover in vivo by using click chemistry. Proceedings of the National Academy of Sciences 105: 15779-15784

Junod SL, Kelich JM, Ma J \& Yang W (2020) Nucleocytoplasmic transport of intrinsically disordered proteins studied by high-speed super-resolution microscopy. Protein Sci 29: 1459-1472

Kabashi E, Valdmanis PN, Dion P, Spiegelman D, McConkey BJ, Velde CV, Bouchard J-P, Lacomblez L, Pochigaeva K, Salachas F, et al (2008) TARDBP mutations in individuals with sporadic and familial amyotrophic lateral sclerosis. Nat Genet 40: $572-574$

Kaida D, Motoyoshi H, Tashiro E, Nojima T, Hagiwara M, Ishigami K, Watanabe H, Kitahara T, Yoshida T, Nakajima H, et al (2007) Spliceostatin A targets SF3b and inhibits both splicing and nuclear retention of pre-mRNA. Nat Chem Biol 3: 576-583

Kalab P, Pralle A, Isacoff EY, Heald R \& Weis K (2006) Analysis of a RanGTP-regulated gradient in mitotic somatic cells. Nature 440: $697-701$ 
1121 Kapinos LE, Huang B, Rencurel C \& Lim RYH (2017) Karyopherins regulate nuclear pore complex barrier

1122

1123

1124

1125

1126

1127

1128

1129

1130

1131

1132

1133

1134

1135

1136

1137

1138

1139

1140

1141

1142

1143

1144

1145

1146

1147

1148

1149

1150

1151

1152

1153

1154

1155

1156

1157

1158

1159

1160

1161

1162

1163

1164

1165

1166

1167

1168

1169

1170

1171

1172

1173

1174 and transport function. The Journal of Cell Biology 216: 3609-3624

Kilchert C, Wittmann S \& Vasiljeva $L$ (2016) The regulation and functions of the nuclear RNA exosome complex. Nat Rev Mol Cell Bio 17: 227-239

Kondo Y, Oubridge C, Roon A-MM van \& Nagai K (2015) Crystal structure of human U1 snRNP, a small nuclear ribonucleoprotein particle, reveals the mechanism of 5' splice site recognition. eLife 4: e04986

Kotake Y, Sagane K, Owa T, Mimori-Kiyosue Y, Shimizu H, Uesugi M, Ishihama Y, Iwata M \& Mizui Y (2007) Splicing factor SF3b as a target of the antitumor natural product pladienolide. Nat Chem Biol 3: 570-575

Kovacs GG, Murrell JR, Horvath S, Haraszti L, Majtenyi K, Molnar MJ, Budka H, Ghetti B \& Spina S (2009) TARDBP variation associated with frontotemporal dementia, supranuclear gaze palsy, and chorea. Movement Disord 24: 1842-1847

Lebedeva S, Jens M, Theil K, Schwanhäusser B, Selbach M, Landthaler M \& Rajewsky N (2011) Transcriptome-wide Analysis of Regulatory Interactions of the RNA-Binding Protein HuR. Mol Cell 43: 340-352

Lee Y \& Rio DC (2015) Mechanisms and Regulation of Alternative Pre-mRNA Splicing. Annu Rev Biochem 84: 1-33

Lin DH, Correia AR, Cai SW, Huber FM, Jette CA \& Hoelz A (2018) Structural and functional analysis of mRNA export regulation by the nuclear pore complex. Nat Commun 9: 2319

Ling JP, Pletnikova O, Troncoso JC \& Wong PC (2015) TDP-43 repression of nonconserved cryptic exons is compromised in ALS-FTD. Science 349: 650-655

Ling JP, Wilks C, Charles R, Leavey PJ, Ghosh D, Jiang L, Santiago CP, Pang B, Venkataraman A, Clark $\mathrm{BS}$, et al (2020) ASCOT identifies key regulators of neuronal subtype-specific splicing. Nat Commun 11: 137

Ling S-C, Polymenidou M \& Cleveland DW (2013) Converging mechanisms in ALS and FTD: disrupted RNA and protein homeostasis. Neuron 79: 416-438

Lukavsky PJ, Daujotyte D, Tollervey JR, Ule J, Stuani C, Buratti E, Baralle FE, Damberger FF \& Allain FHT (2013) Molecular basis of UG-rich RNA recognition by the human splicing factor TDP-43. Nature Structural \& Molecular Biology 20: 1443-1449

Maharana S, Wang J, Papadopoulos DK, Richter D, Pozniakovsky A, Poser I, Bickle M, Rizk S, GuillénBoixet J, Franzmann TM, et al (2018) RNA buffers the phase separation behavior of prion-like RNA binding proteins. Science 360: 918-921

Mann JR, Gleixner AM, Mauna JC, Gomes E, DeChellis-Marks MR, Needham PG, Copley KE, Hurtle B, Portz B, Pyles NJ, et al (2019) RNA Binding Antagonizes Neurotoxic Phase Transitions of TDP-43. Neuron 102: 321-338.e8

Massey AJ, Williamson DS, Browne H, Murray JB, Dokurno P, Shaw T, Macias AT, Daniels Z, Geoffroy S, Dopson $\mathrm{M}$, et al (2010) A novel, small molecule inhibitor of Hsc70/Hsp70 potentiates Hsp90 inhibitor induced apoptosis in HCT116 colon carcinoma cells. Cancer Chemoth Pharm 66: 535-545

Mauger O, Lemoine F \& Scheiffele P (2016) Targeted Intron Retention and Excision for Rapid Gene Regulation in Response to Neuronal Activity. Neuron 92: 1266-1278

Merendino L, Guth S, Bilbao D, Martínez C \& Valcárcel J (1999) Inhibition of msl-2 splicing by Sex-lethal reveals interaction between U2AF35 and the 3' splice site AG. Nature 402: 838-841

Michael WM, Choi M \& Dreyfuss G (1995) A nuclear export signal in hnRNP A1: a signal-mediated, temperature-dependent nuclear protein export pathway. Cell 83: 415-422

Michael WM, Eder PS \& Dreyfuss G (1997) The K nuclear shuttling domain: a novel signal for nuclear import and nuclear export in the hnRNP K protein. The EMBO Journal 16: 3587-3598

Mohr D, Frey S, Fischer T, Güttler T \& Görlich D (2009) Characterisation of the passive permeability barrier of nuclear pore complexes. The EMBO Journal 28: 2541-2553

Molliex A, Temirov J, Lee J, Coughlin M, Kanagaraj AP, Kim HJ, Mittag T \& Taylor JP (2015) Phase separation by low complexity domains promotes stress granule assembly and drives pathological fibrillization. Cell 163: 123-133

Mompeán M, Romano V, Pantoja-Uceda D, Stuani C, Baralle FE, Buratti E \& Laurents DV (2017) Point mutations in the $\mathrm{N}$-terminal domain of transactive response DNA-binding protein $43 \mathrm{kDa}$ (TDP-43) compromise its stability, dimerization, and functions. J Biol Chem 292: 11992-12006 
1175 Nakielny S \& Dreyfuss G (1996) The hnRNP C proteins contain a nuclear retention sequence that can override nuclear export signals. J Cell Biology 134: 1365-1373

Nakielny S \& Dreyfuss G (1999) Transport of Proteins and RNAs in and out of the Nucleus. Cell 99: 677690

Napetschnig J, Kassube SA, Debler EW, Wong RW, Blobel G \& Hoelz A (2009) Structural and functional analysis of the interaction between the nucleoporin Nup214 and the DEAD-box helicase Ddx19. Proc National Acad Sci 106: 3089-3094

Neumann M, Sampathu DM, Kwong LK, Truax AC, Micsenyi MC, Chou TT, Bruce J, Schuck T, Grossman M, Clark CM, et al (2006) Ubiquitinated TDP-43 in Frontotemporal Lobar Degeneration and Amyotrophic Lateral Sclerosis. Science 314: 130-133

Nguyen TM, Kabotyanski EB, Reineke LC, Shao J, Xiong F, Lee J-H, Dubrulle J, Johnson H, Stossi F, Tsoi PS, et al (2019) The SINEB1 element in the long non-coding RNA Malat1 is necessary for TDP-43 proteostasis. Nucleic Acids Res 48: 2621-2642

Nishimura AL, Zupunski V, Troakes C, Kathe C, Fratta P, Howell M, Gallo J-M, Hortobágyi T, Shaw CE \& Rogelj B (2010) Nuclear import impairment causes cytoplasmic trans-activation response DNA-binding protein accumulation and is associated with frontotemporal lobar degeneration. Brain 133: 1763-1771

Nostrand ELV, Freese P, Pratt GA, Wang X, Wei X, Xiao R, Blue SM, Chen J-Y, Cody NAL, Dominguez D, et al (2020) A large-scale binding and functional map of human RNA-binding proteins. Nature 583: 711719

Nussbacher JK, Tabet R, Yeo GW \& Lagier-Tourenne C (2019) Disruption of RNA Metabolism in Neurological Diseases and Emerging Therapeutic Interventions. Neuron 102: 294-320

O'Brien K, Matlin AJ, Lowell AM \& Moore MJ (2008) The Biflavonoid Isoginkgetin Is a General Inhibitor of Pre-mRNA Splicing. J Biological Chem 283: 33147-33154

Okamura M, Inose H \& Masuda S (2015) RNA Export through the NPC in Eukaryotes. Genes-basel 6: 124-149

Olson CM, Jiang B, Erb MA, Liang Y, Doctor ZM, Zhang Z, Zhang T, Kwiatkowski N, Boukhali M, Green JL, et al (2018) Pharmacological perturbation of CDK9 using selective CDK9 inhibition or degradation. Nat Chem Biol 14: 163-170

Paci G, Zheng T, Caria J, Zilman A \& Lemke EA (2020) Molecular determinants of large cargo transport into the nucleus. eLife 9: e55963.

Paz I, Kosti I, Ares M, Cline M \& Mandel-Gutfreund Y (2014) RBPmap: a web server for mapping binding sites of RNA-binding proteins. Nucleic Acids Res 42: W361-W367

Pinarbasi ES, Cağatay T, Fung HYJ, Li YC, Chook YM \& Thomas PJ (2018) Active nuclear import and passive nuclear export are the primary determinants of TDP-43 localization. Scientific reports 8: 7083

Piñol-Roma S \& Dreyfuss G (1992) Shuttling of pre-mRNA binding proteins between nucleus and cytoplasm. Nature 355: 730-732

Polymenidou M, Lagier-Tourenne C, Hutt KR, Huelga SC, Moran J, Liang TY, Ling S-C, Sun E, Wancewicz $\mathrm{E}$, Mazur C, et al (2011) Long pre-mRNA depletion and RNA missplicing contribute to neuronal vulnerability from loss of TDP-43. Nature Neuroscience 14: 459-468

Prasad A, Bharathi V, Sivalingam V, Girdhar A \& Patel BK (2019) Molecular Mechanisms of TDP-43 Misfolding and Pathology in Amyotrophic Lateral Sclerosis. Frontiers in molecular neuroscience 12: 25

Price AJ, Hwang T, Tao R, Burke EE, Rajpurohit A, Shin JH, Hyde TM, Kleinman JE, Jaffe AE \& Weinberger DR (2019) Characterizing the nuclear and cytoplasmic transcriptomes in developing and mature human cortex uncovers new insight into psychiatric disease gene regulation. Genome Res 30: $1-11$

Rafiee M-R, Zagalak JA, Sidorov S, Steinhauser S, Davey K, Ule J \& Luscombe NM (2021) Chromatincontact atlas reveals disorder-mediated protein interactions and moonlighting chromatin-associated RBPs. Biorxiv: doi: 10.1101/2020.07.13.200212

Ribbeck K \& Görlich D (2002) The permeability barrier of nuclear pore complexes appears to operate via hydrophobic exclusion. The EMBO Journal 21: 2664-2671

Roczniak-Ferguson A \& Ferguson SM (2019) Pleiotropic requirements for human TDP-43 in the regulation of cell and organelle homeostasis. Life Sci Alliance 2: e201900358

Saini H, Bicknell AA, Eddy SR \& Moore MJ (2019) Free circular introns with an unusual branchpoint in neuronal projections. eLife 8: e47809 
1229

1230

1231

1232

1233

1234

1235

1236

1237

1238

1239

1240

1241

1242

1243

1244

1245

1246

1247

1248

1249

1250

1251

1252

1253

1254

1255

1256

1257

1258

1259

1260

1261

1262

1263

1264

1265

1266

1267

1268

1269

1270

1271

1272

1273

1274

1275

1276

1277

1278

1279

1280

1281

Sato M, Muguruma N, Nakagawa T, Okamoto K, Kimura T, Kitamura S, Yano H, Sannomiya K, Goji T, Miyamoto $\mathrm{H}$, et al (2014) High antitumor activity of pladienolide B and its derivative in gastric cancer. Cancer Sci 105: 110-116

Sharifi S \& Bierhoff H (2018) Regulation of RNA Polymerase I Transcription in Development, Disease, and Aging. Annu Rev Biochem 87: 1-23

Silanes IL de, Zhan M, Lal A, Yang X \& Gorospe M (2004) Identification of a target RNA motif for RNAbinding protein HuR. P Natl Acad Sci Usa 101: 2987-2992

Snapp EL, Hegde RS, Francolini M, Lombardo F, Colombo S, Pedrazzini E, Borgese N \& LippincottSchwartz J (2003) Formation of stacked ER cisternae by low affinity protein interactions. J Cell Biology 163: 257-269

Soh S, Byrska M, Kandere-Grzybowska K \& Grzybowski BA (2010) Reaction-Diffusion Systems in Intracellular Molecular Transport and Control. Angewandte Chemie Int Ed 49: 4170-4198

Sreedharan J, Blair IP, Tripathi VB, Hu X, Vance C, Rogelj B, Ackerley S, Durnall JC, Williams KL, Buratti E, et al (2008) TDP-43 Mutations in Familial and Sporadic Amyotrophic Lateral Sclerosis. Science 319: 1668-1672

Sun H, Chen W, Chen L \& Zheng W (2021) Exploring the molecular basis of UG-rich RNA recognition by the human splicing factor TDP-43 using molecular dynamics simulation and free energy calculation. $J$ Comput Chem 42: 1670-1680

Talhouarne GJS \& Gall JG (2018) Lariat intronic RNAs in the cytoplasm of vertebrate cells. Proc National Acad Sci 115: 201808816

Tank EM, Figueroa-Romero C, Hinder LM, Bedi K, Archbold HC, Li X, Weskamp K, Safren N, PaezColasante X, Pacut C, et al (2018) Abnormal RNA stability in amyotrophic lateral sclerosis. Nat Commun 9: 2845

Timney BL, Raveh B, Mironska R, Trivedi JM, Kim SJ, Russel D, Wente SR, Sali A \& Rout MP (2016) Simple rules for passive diffusion through the nuclear pore complex. The Journal of Cell Biology 215: 57-76

Tollervey JR, Curk T, Rogelj B, Briese M, Cereda M, Kayikci M, König J, Hortobágyi T, Nishimura AL, Zupunski V, et al (2011) Characterizing the RNA targets and position-dependent splicing regulation by TDP-43. Nature Neuroscience 14: 452-458

Tuck AC \& Tollervey D (2013) A Transcriptome-wide Atlas of RNP Composition Reveals Diverse Classes of mRNAs and IncRNAs. Cell 154: 996-1009

Tyssowski KM \& Gray JM (2019) The neuronal stimulation-transcription coupling map. Curr Opin Neurobiol 59: 87-94

Wang C, Duan Y, Duan G, Wang Q, Zhang K, Deng X, Qian B, Gu J, Ma Z, Zhang S, et al (2020) Stress Induces Dynamic, Cytotoxicity-Antagonizing TDP-43 Nuclear Bodies via Paraspeckle LncRNA NEAT1Mediated Liquid-Liquid Phase Separation. Molecular Cell 79: 443-458.e7

Weskamp K, Tank EM, Miguez R, McBride JP, Gómez NB, White M, Lin Z, Gonzalez CM, Serio A, Sreedharan J, et al (2020) Shortened TDP43 isoforms upregulated by neuronal hyperactivity drive TDP43 pathology in ALS. Journal of Clinical Investigation 130: 1139-1155

Wheeler EC, Nostrand ELV \& Yeo GW (2018) Advances and challenges in the detection of transcriptomewide protein-RNA interactions. Wiley Interdiscip Rev Rna 9

Whitehurst AW, Wilsbacher JL, You Y, Luby-Phelps K, Moore MS \& Cobb MH (2002) ERK2 enters the nucleus by a carrier-independent mechanism. Proc National Acad Sci 99: 7496-7501

Winton MJ, Igaz LM, Wong MM, Kwong LK, Trojanowski JQ \& Lee VMY (2008) Disturbance of nuclear and cytoplasmic TAR DNA-binding protein (TDP-43) induces disease-like redistribution, sequestration, and aggregate formation. The Journal of biological chemistry 283: 13302-13309

Wu S, Romfo CM, Nilsen TW \& Green MR (1999) Functional recognition of the 3' splice site AG by the splicing factor U2AF35. Nature 402: 832-835

Yu H, Lu S, Gasior K, Singh D, Vazquez-Sanchez S, Tapia O, Toprani D, Beccari MS, Yates JR, Cruz SD, et al (2020) HSP70 chaperones RNA-free TDP-43 into anisotropic intranuclear liquid spherical shells. Science

Zacco E, Martin SR, Thorogate R \& Pastore A (2018) The RNA-Recognition Motifs of TAR DNA-Binding Protein 43 May Play a Role in the Aberrant Self-Assembly of the Protein. Front Mol Neurosci 11: 372 
bioRxiv preprint doi: https://doi.org/10.1101/2021.08.24.457459; this version posted August 24, 2021. The copyright holder for this preprint (which was not certified by peer review) is the author/funder. All rights reserved. No reuse allowed without permission.

1282 Zaepfel BL \& Rothstein JD (2021) RNA Is a Double-Edged Sword in ALS Pathogenesis. Front Cell $1283 \quad$ Neurosci 15: 708181

1284 Zorio DAR \& Blumenthal T (1999) Both subunits of U2AF recognize the 3' splice site in Caenorhabditis 1285 elegans. Nature 402: 835-838 


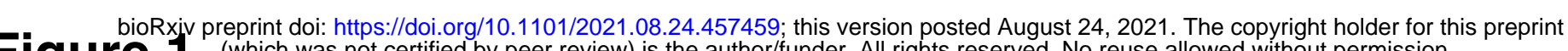
1010 (which was not certified by peer review) is the author/funder. All rights reserved. No reuse allowed without permission.

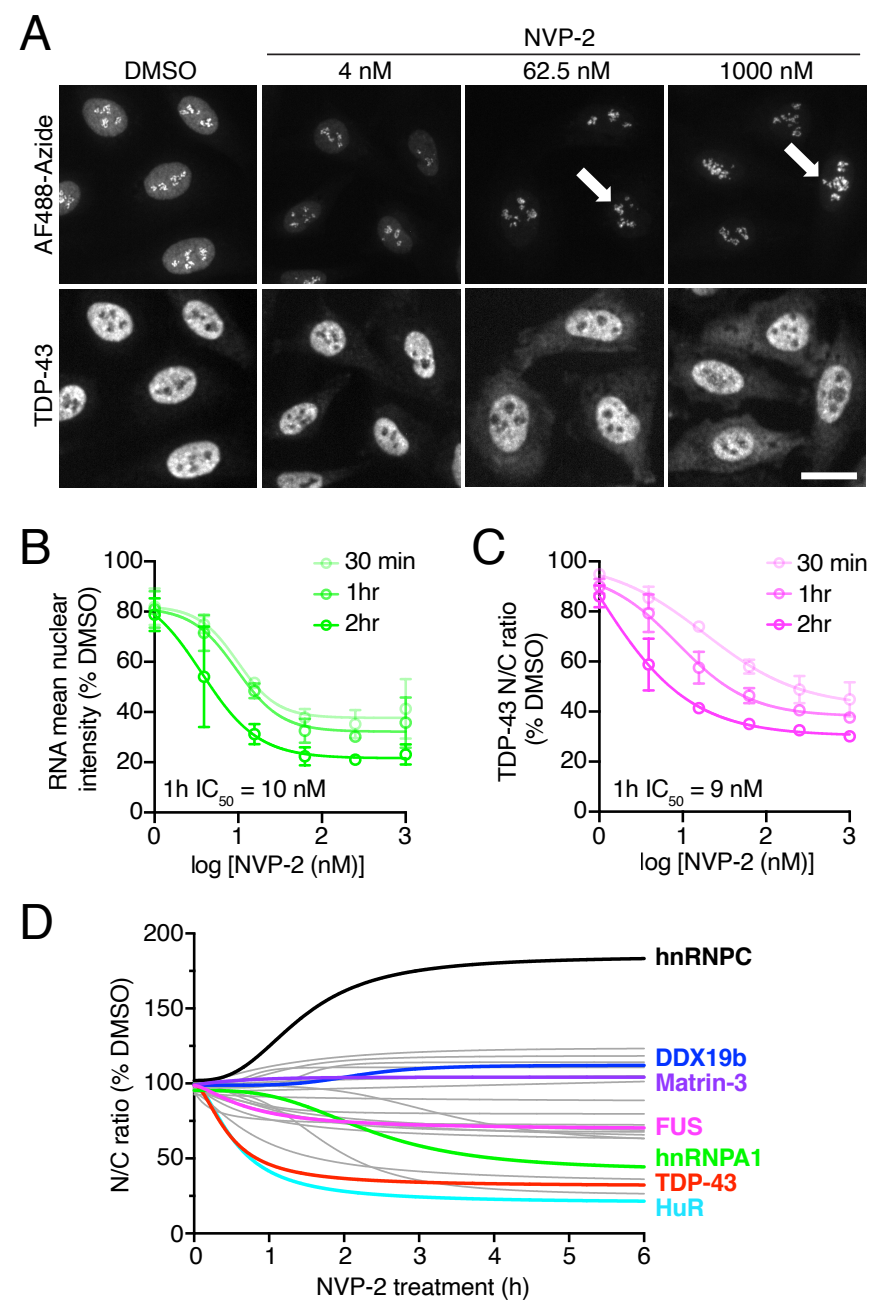


A

N/C ratio (\% time 0)

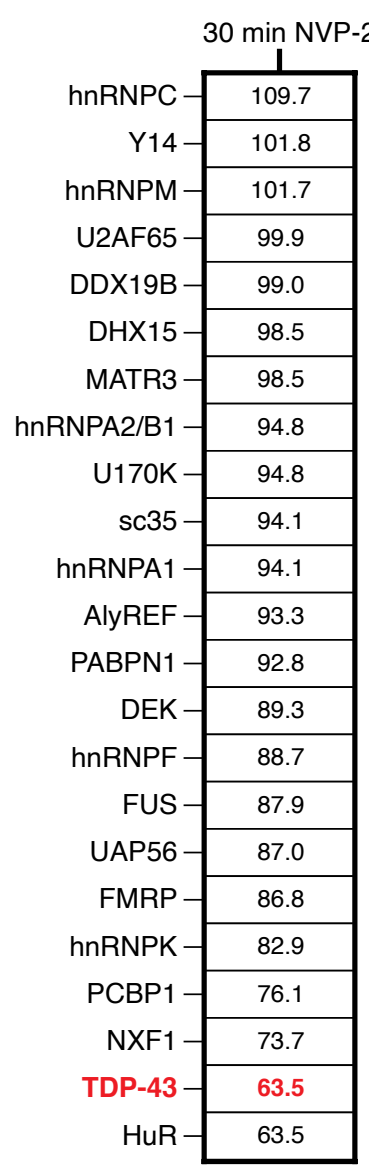

B

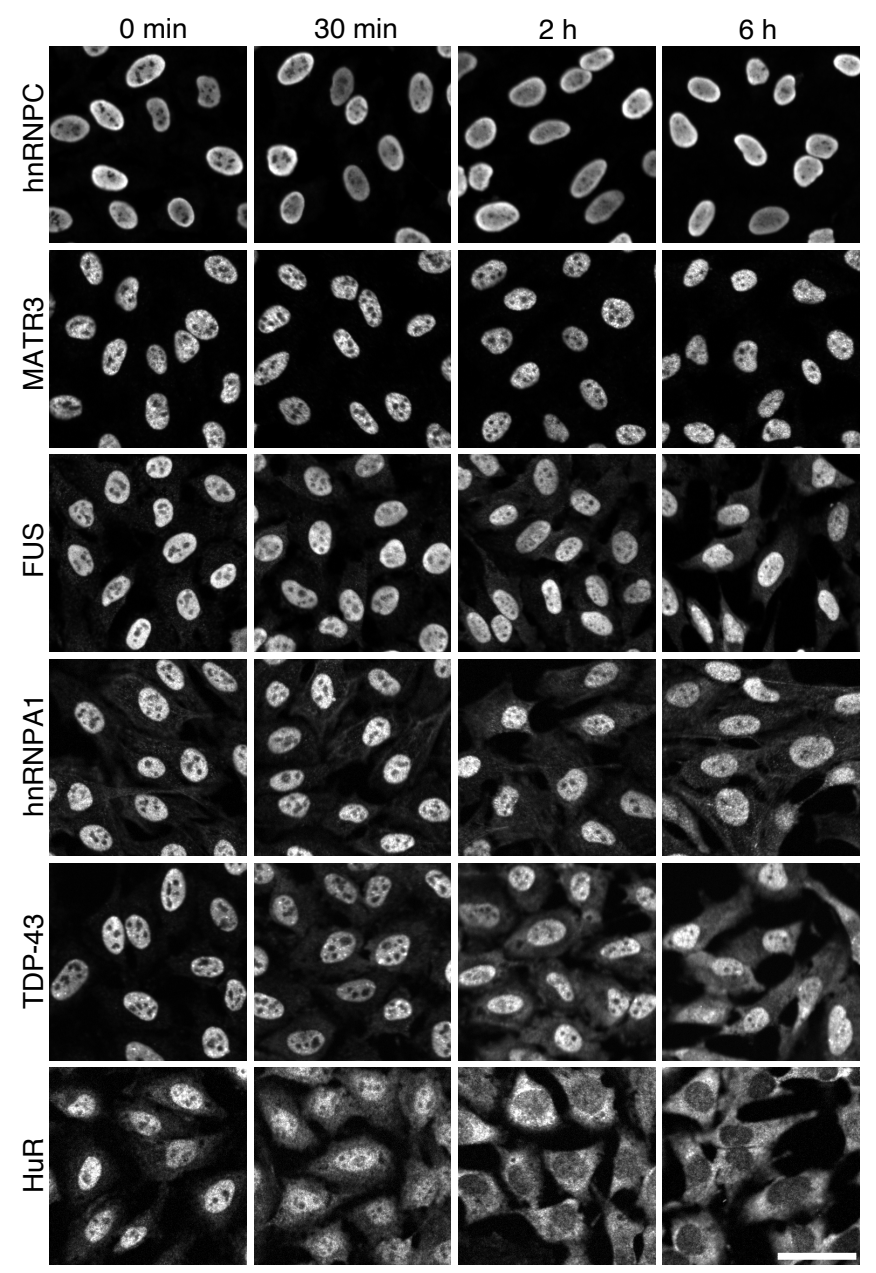




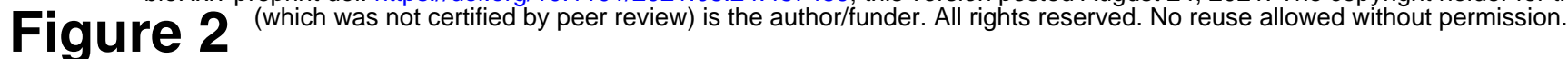

A
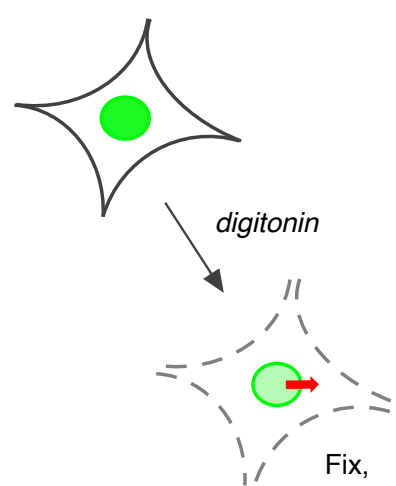

TDP-43 IF
B

?

足

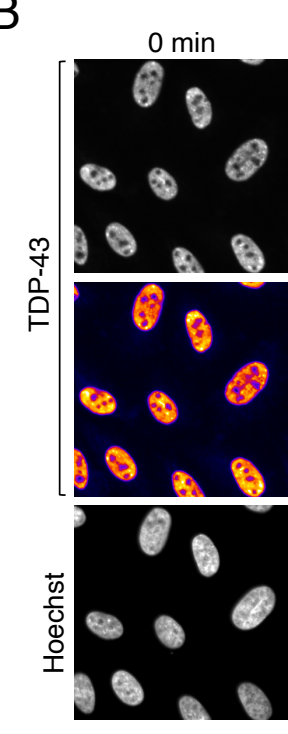

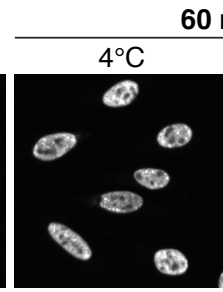
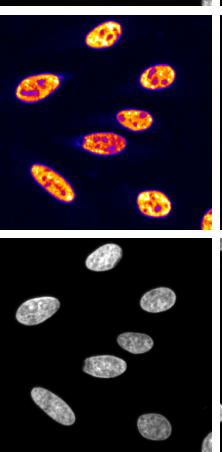

60 min

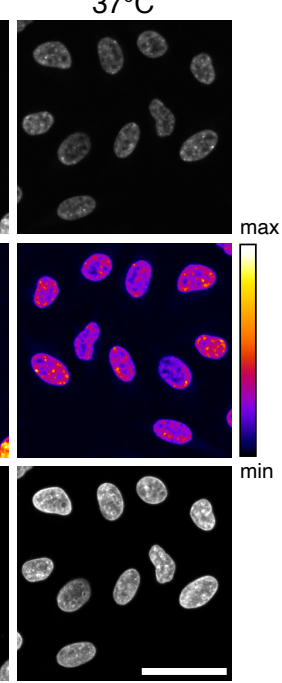

C

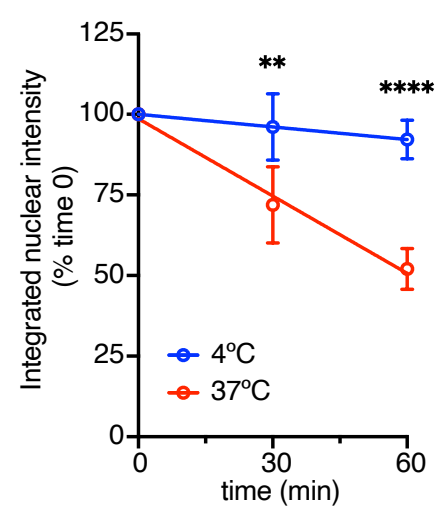

D

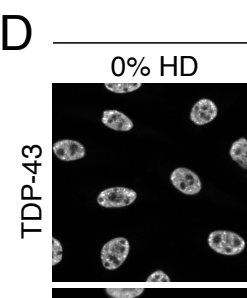

$4^{\circ} \mathrm{C}$

$\begin{array}{cc}5 \% & H D \\ 8 & 0 \\ 0 & 0 \\ 0 & 0\end{array}$

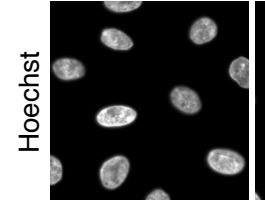
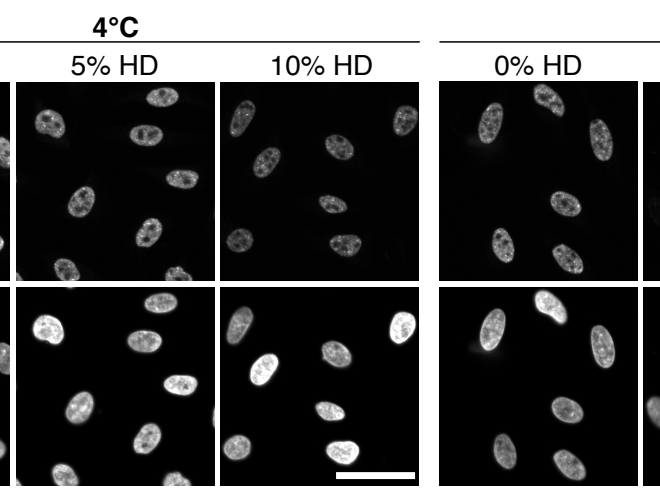

$37^{\circ} \mathrm{C}$
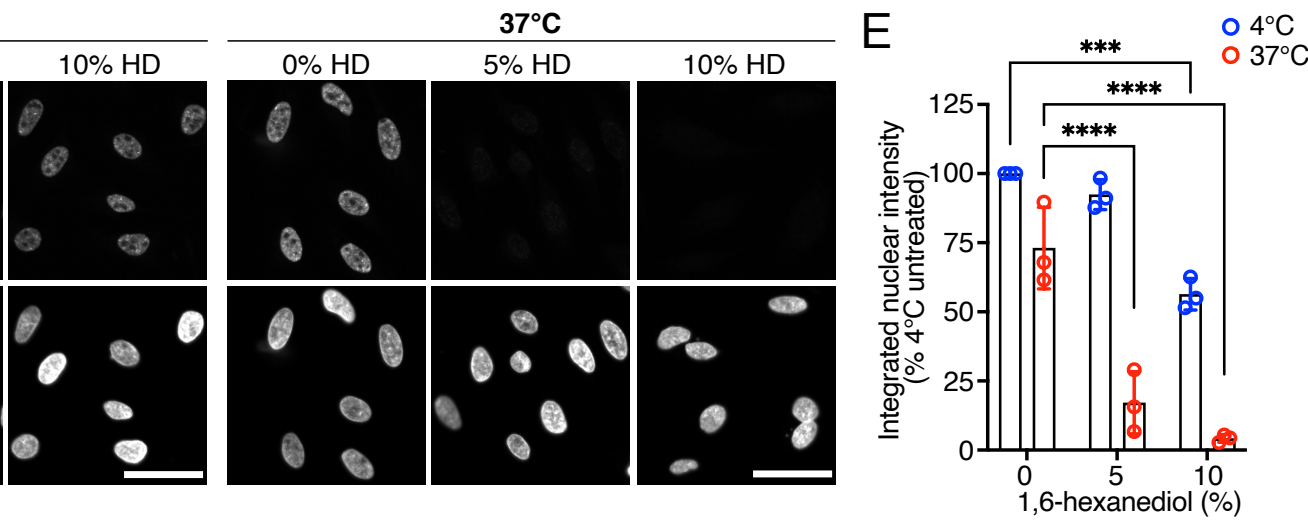

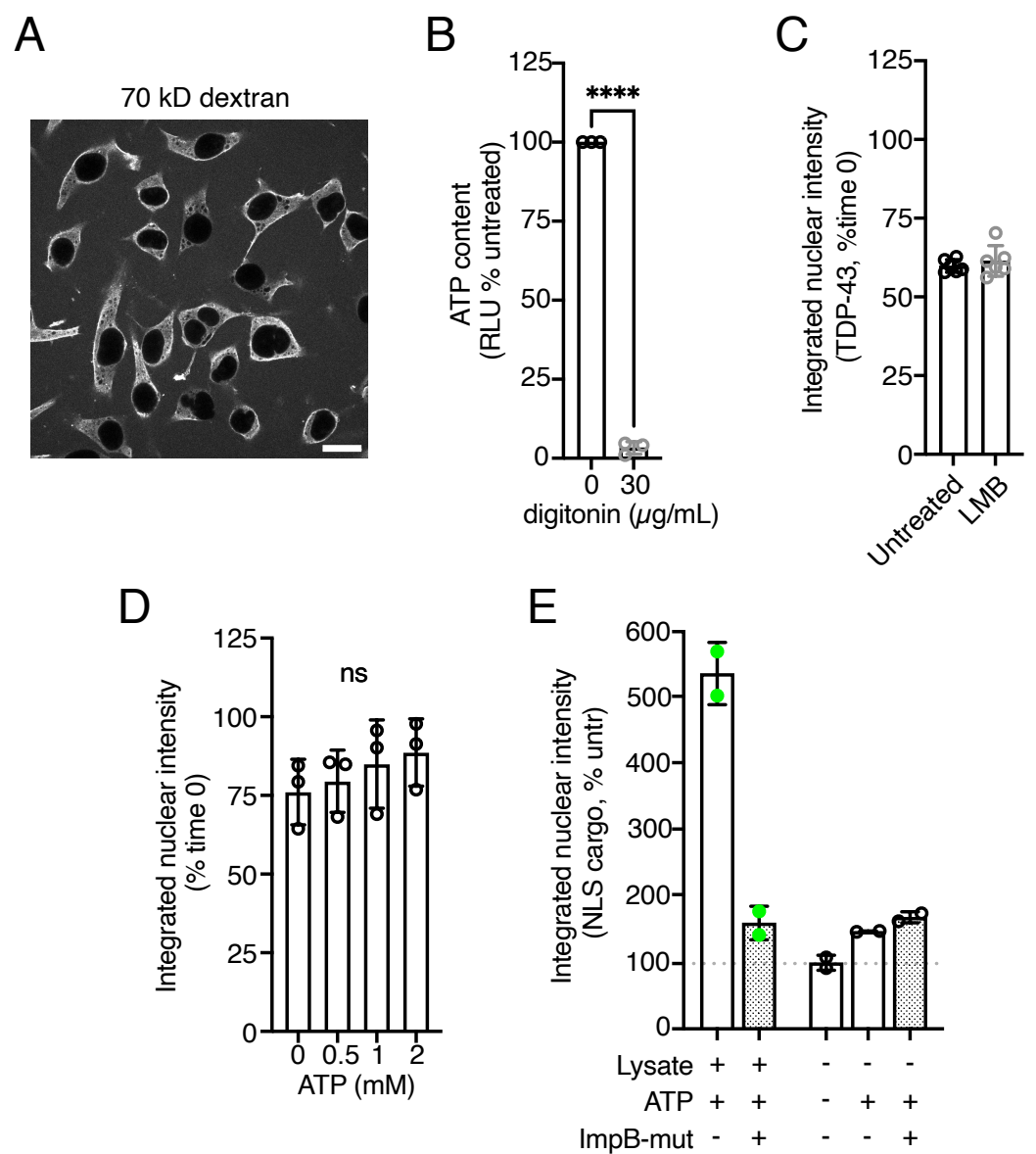
A

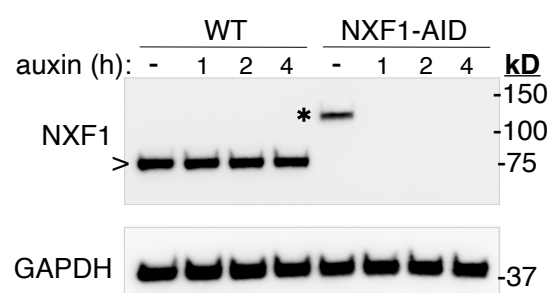

D

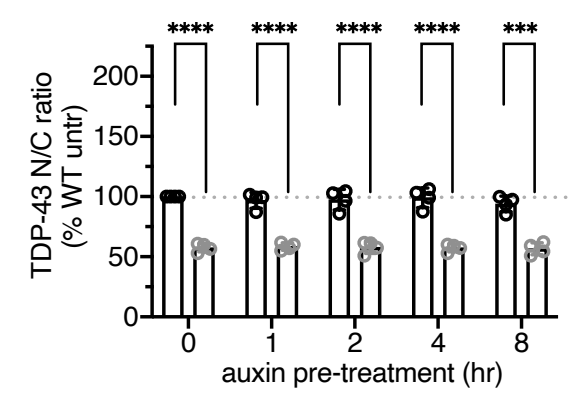

B

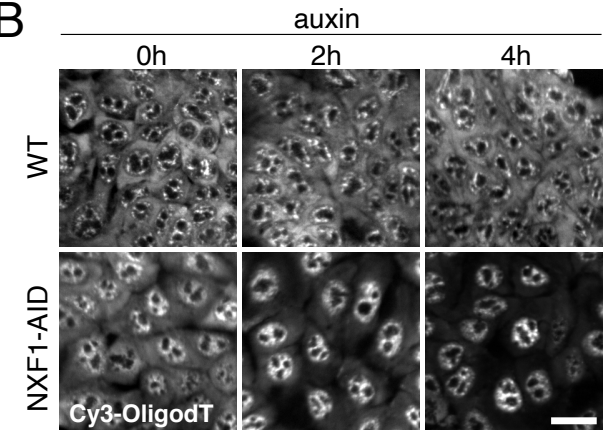

DLD1-NXF1-AID

- -NVP-2 ○ +NVP-2

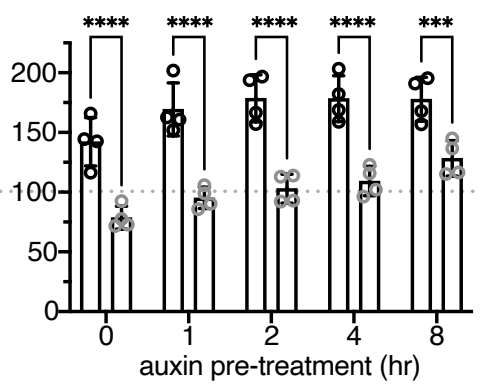

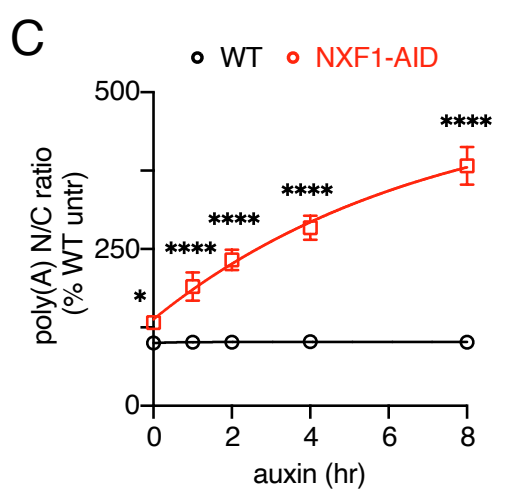

E

NVP-2-induced nuclear exit

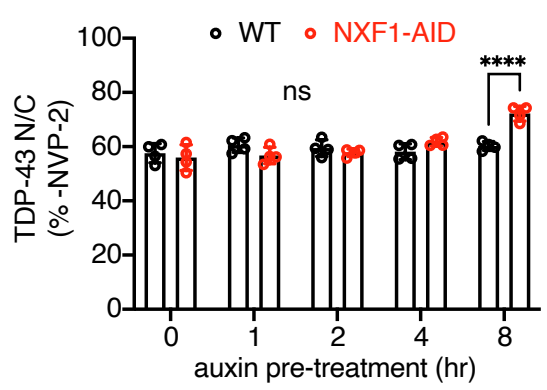


A

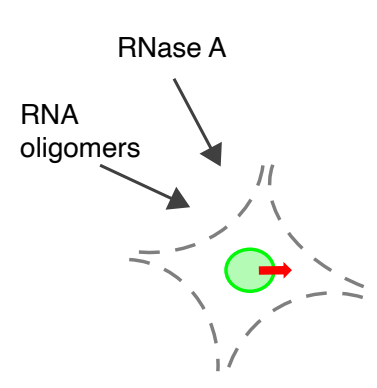

permeabilized cells $30 \mathrm{~min}$
B

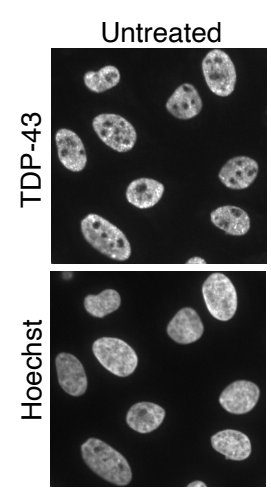

RNase $\mathrm{A}\left(4^{\circ} \mathrm{C}\right)$

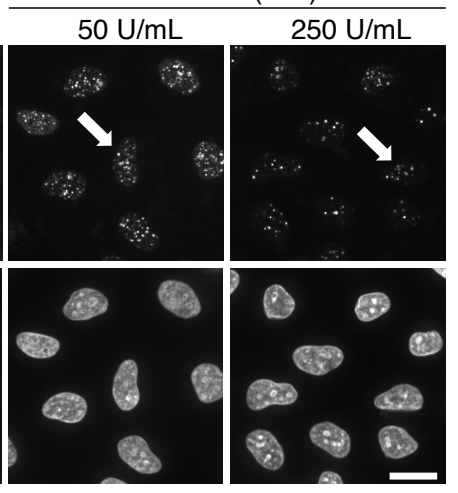

C

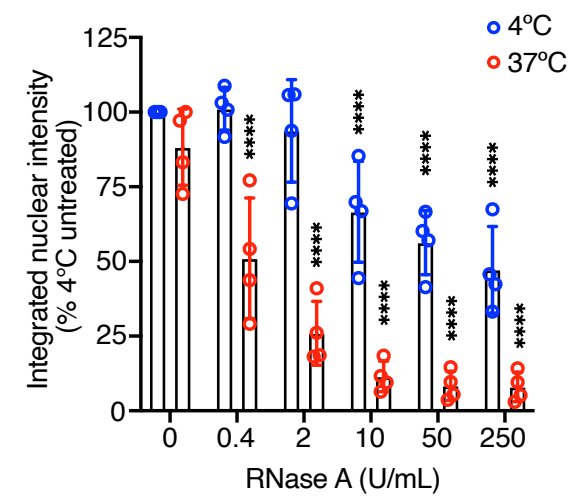

$\mathrm{F}$

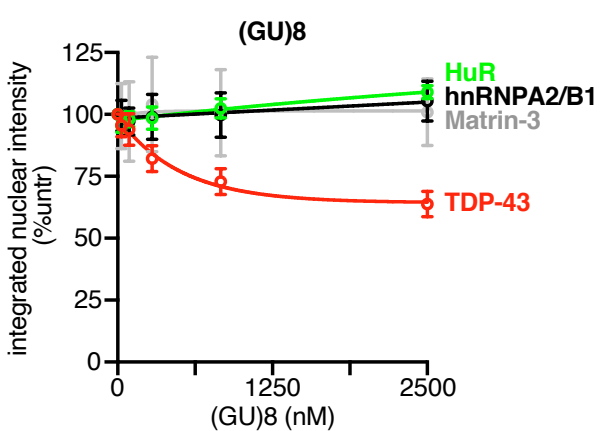

$4^{\circ} \mathrm{C}$

$37^{\circ} \mathrm{C}$

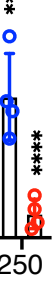

G

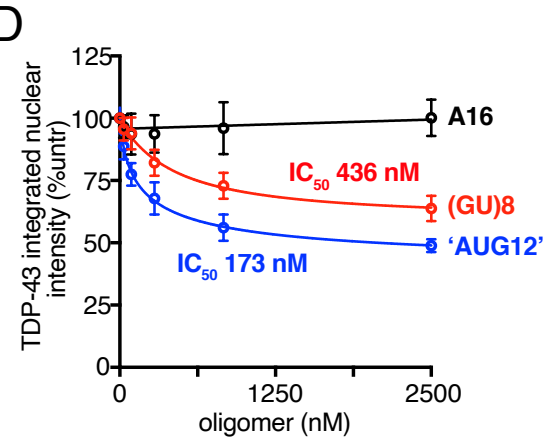

E

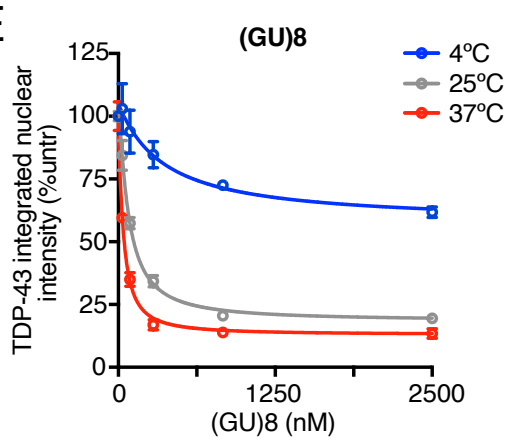

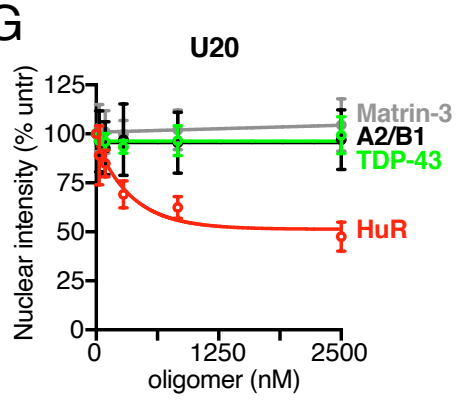
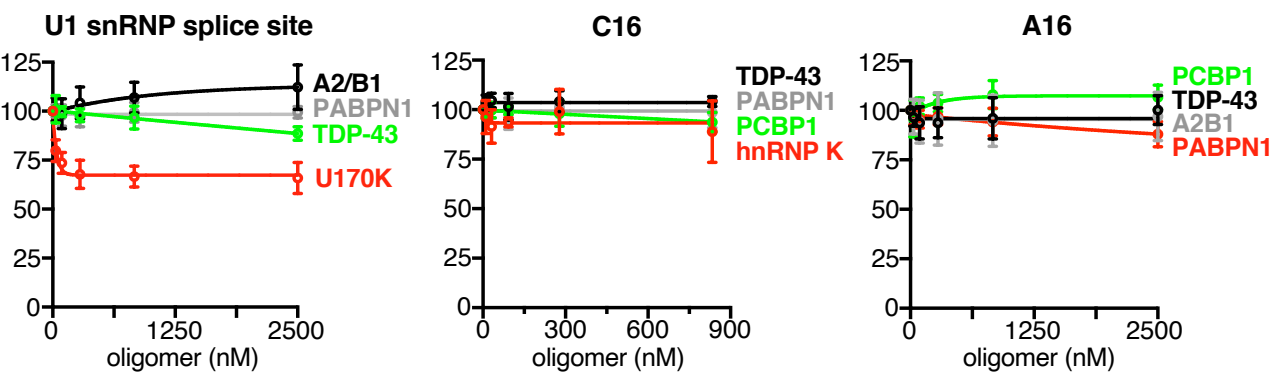

$\mathrm{H}$

Protected RNA oligomers
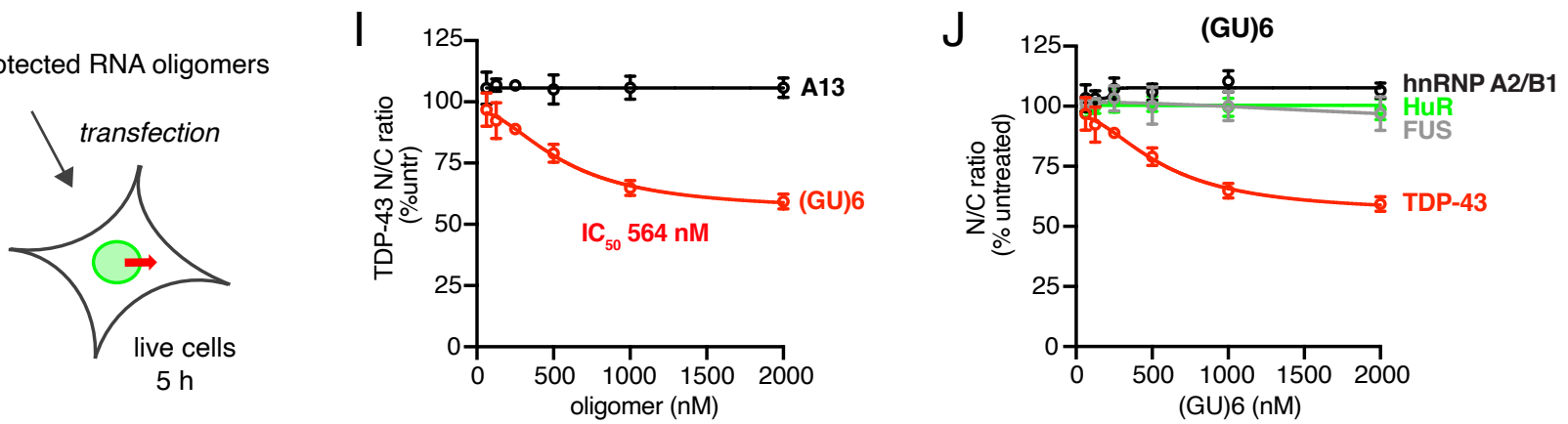

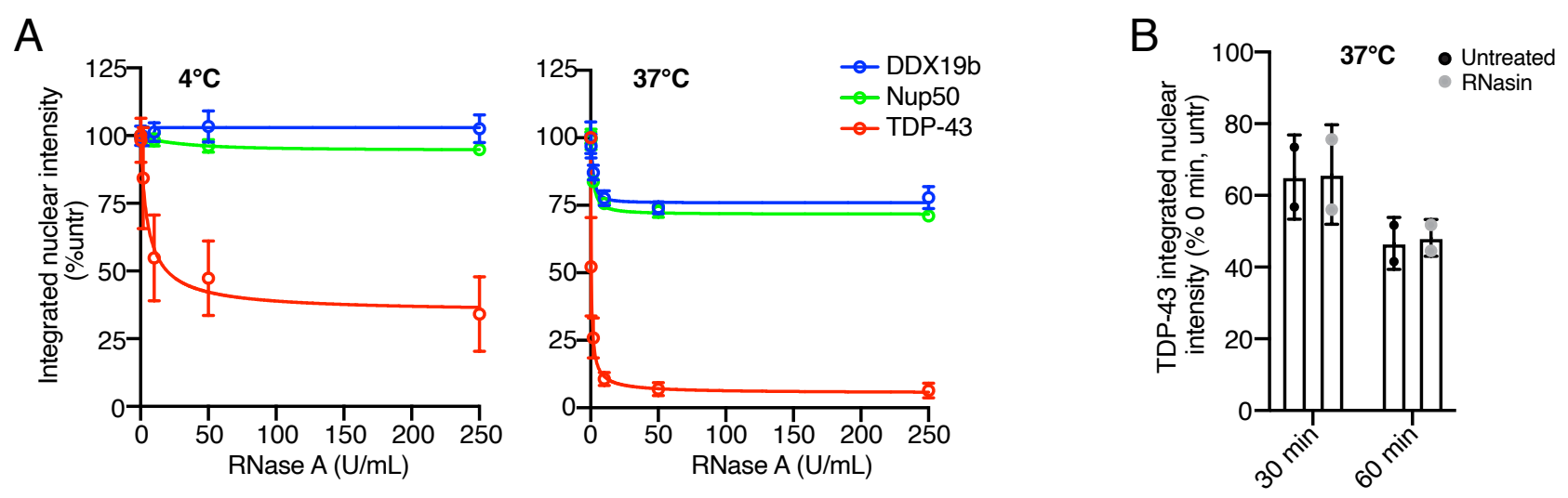
A

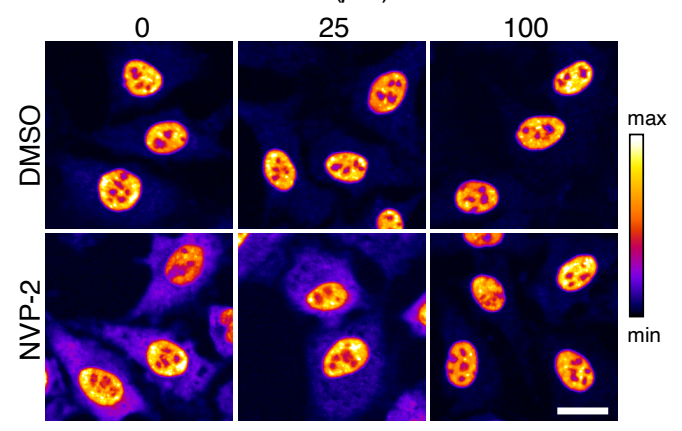

D

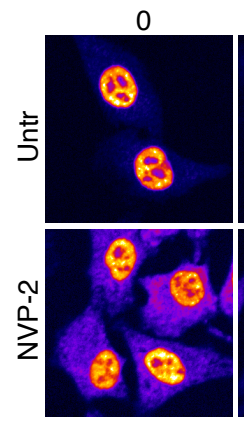

B

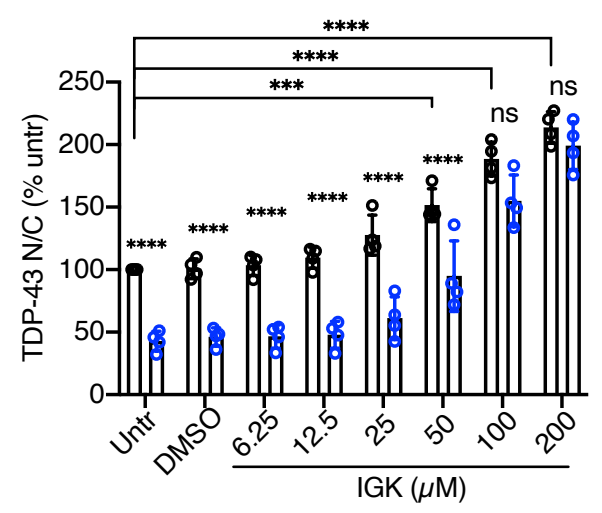

E

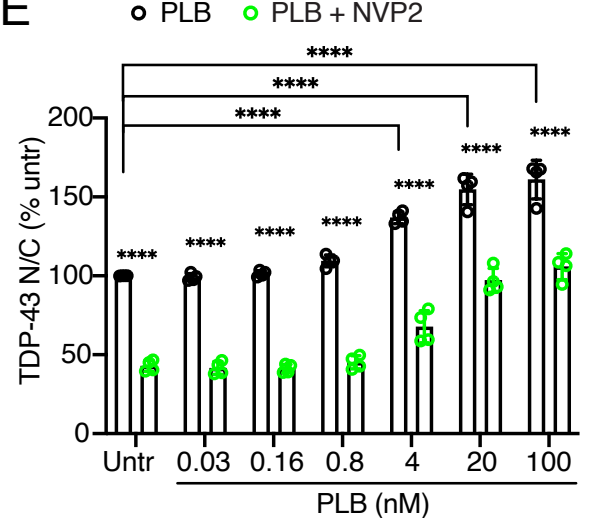

C

NVP-2-induced nuclear exit

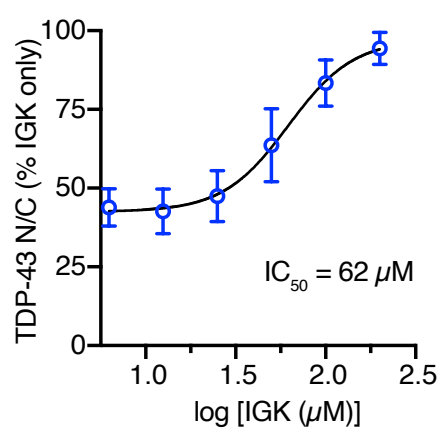

F

NVP-2-induced nuclear exit

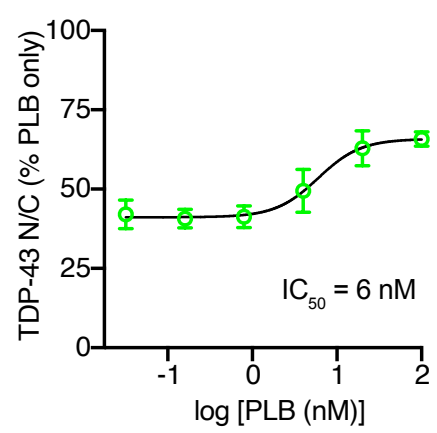



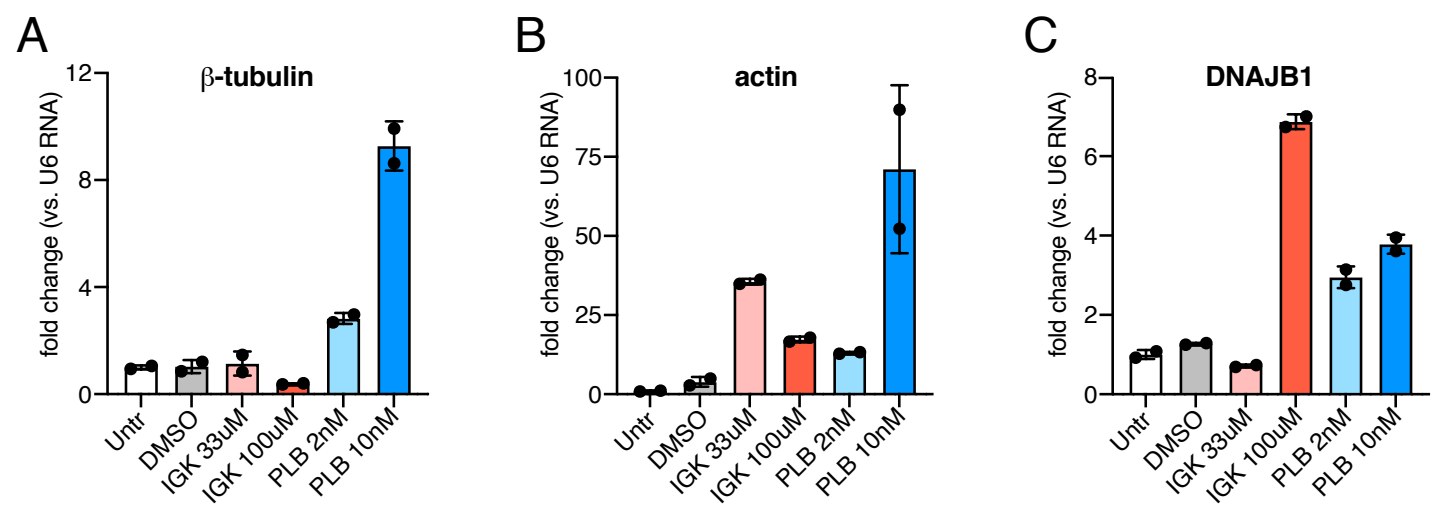
Figure 6

A
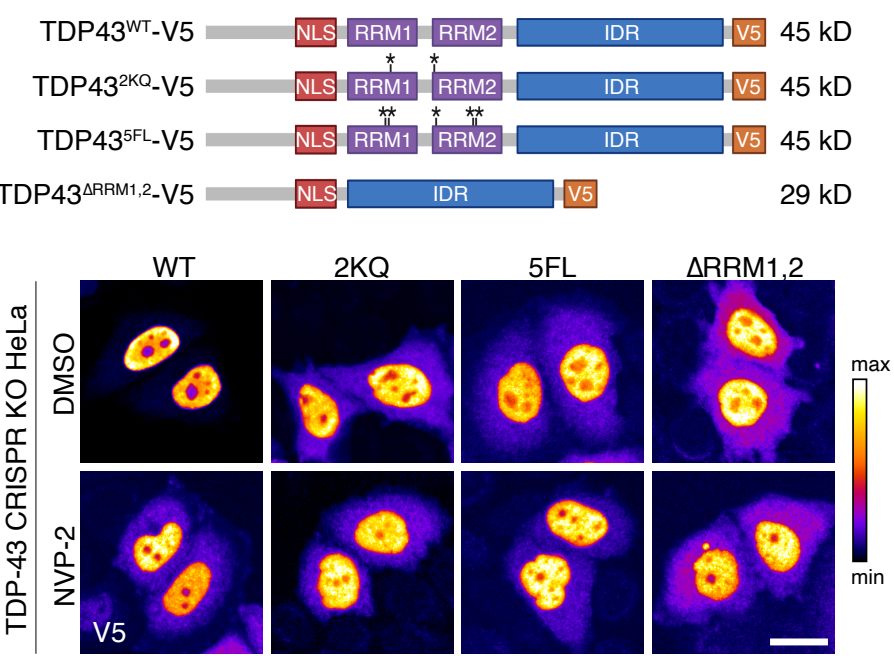

C
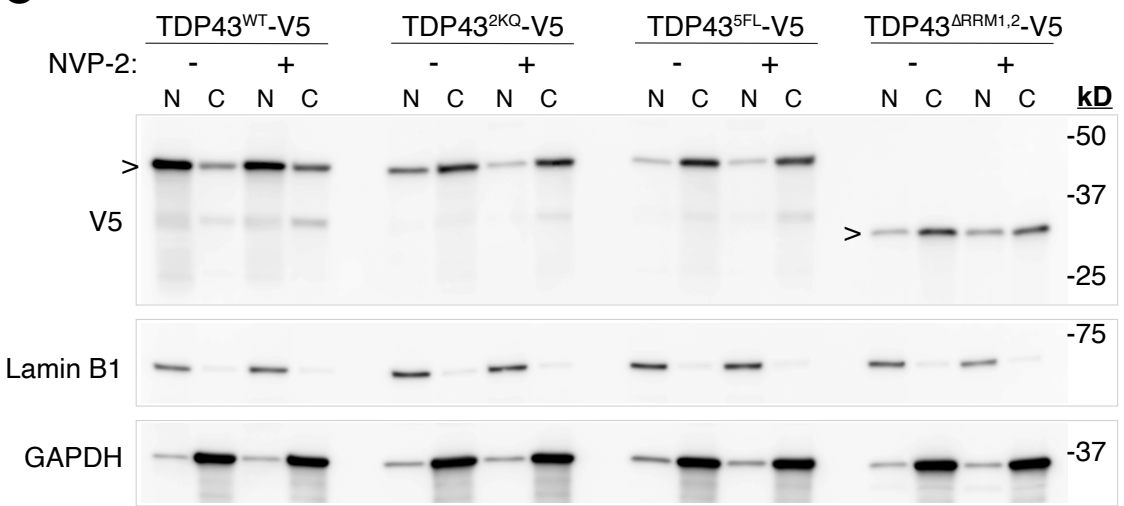

B

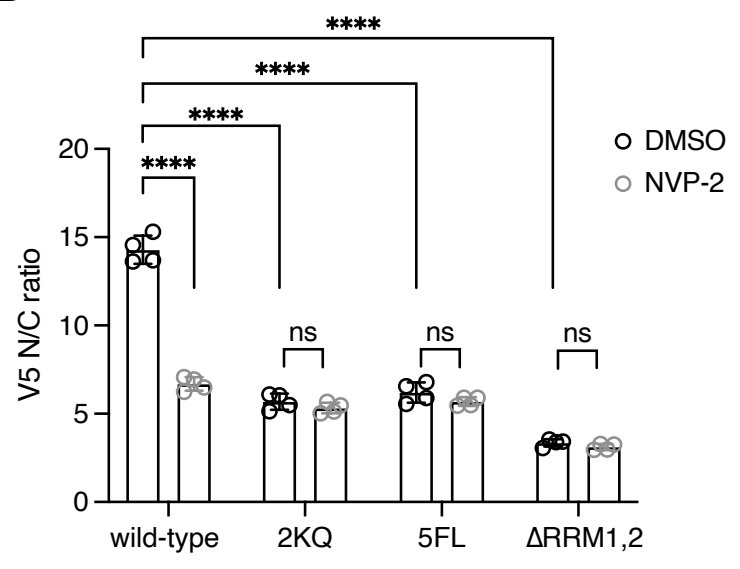

D ODMSO ONVP-2

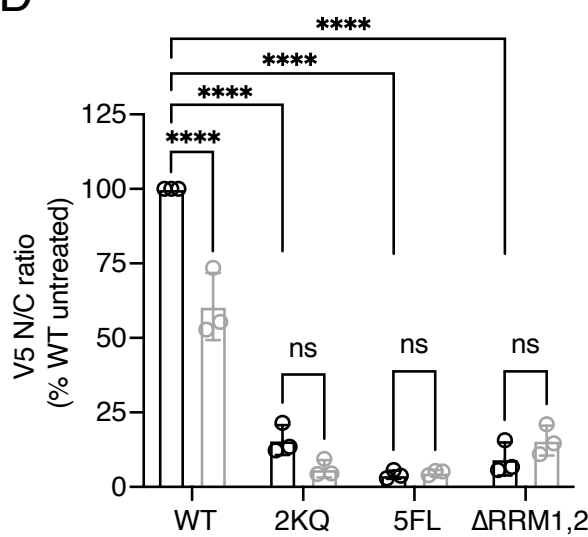


Supplemental figure 6

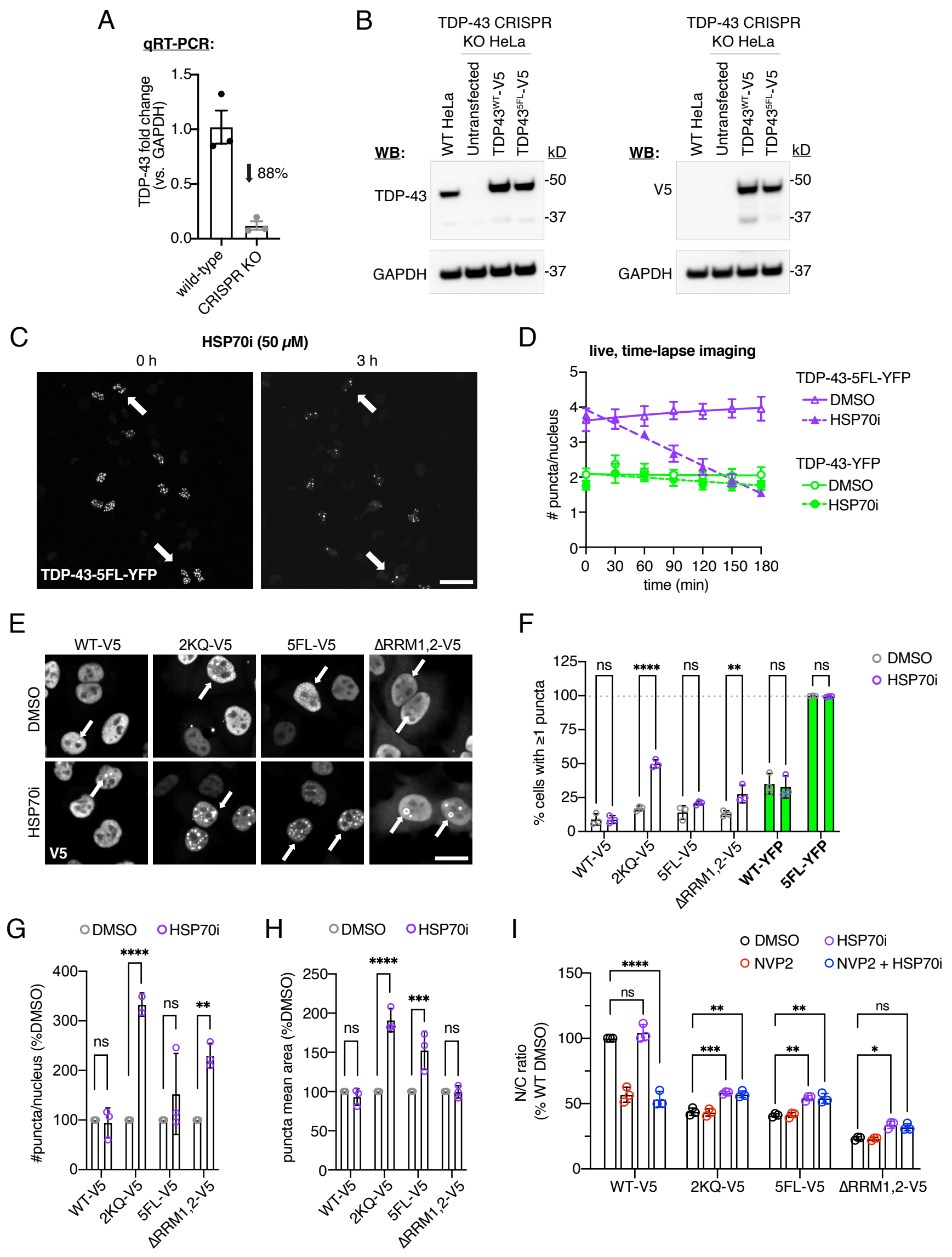


bioRxiv preprint doi: https://doi.org/10.1101/2021.08.24.457459; this version posted August 24, 2021. The copyright holder for this preprint

Figure 7

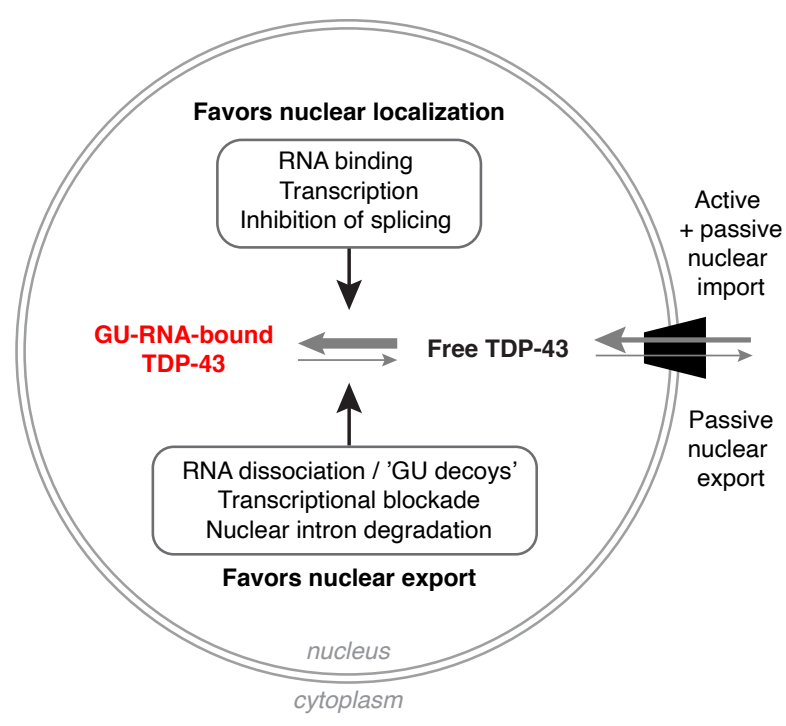

